Journal of Advanced Engineering Technology (JAET), Vol. 39, No. 1. January 2020

\title{
ASSESSMENT OF ENVIRONMENTAL SUSTAINABILITY OF TRADITIONAL AND CONTEMPORARY BUILDINGS IN EGYPT IN THE LIGHT OF COMPARATIVE ANALYSIS OF GREEN ARCHITECTURE ASSESSMENT SYSTEMS
}

\author{
Mohammed Azmi Ahmed ${ }^{1}$, Ashraf Abu El-Ayoun Abd El-Rahim², Rasha Maher Abdel-Wahab ${ }^{3}$ \\ ${ }^{1}$ Department of Architecture, Faculty of Engineering, Assiut University, Assiut, Egypt \\ ${ }^{2,3}$ Department of Architecture, Faculty of Engineering, Minia University, Minia, Egypt
}

\begin{abstract}
:-
Buildings impact directly and indirectly on the environment during the life cycle of the building from construction to demolition. It consumes energy, water and raw materials, produces residues and causes harmful emissions to the environment and the atmosphere, creating the need for building standards for buildings to mitigate their negative impacts on the environment. Natural through sustainable green design,There are many different assessment systems in the world, such as the BREEAM system, the first building classification system in the United Kingdom, which appeared in 1990, and the LEED system, which emerged in the United States in 1998. A number of attempts have been made in Egypt to support the national approach to the application of architecture Green but still Egyptian systems are under study by researchers for the existence of certain deficiencies in some items and application. The research paper relies on the methodology of monitoring, analysis and comparison of some international and local models of the different global and Egyptian evaluation systems in order to reach the common points and clarify the different items to reach the most important elements that should be included in the evaluation system,Traditional and contemporary buildings in Egypt. The paper aims to develop a proposed evaluation system for green architecture in Egypt, and apply it to some buildings representing traditional architecture in Egypt (Beit Al-Suhaimi-House of Cretilia) and buildings representing contemporary architecture (Library of Alexandria-The new American University in the fifth assembly "AUC"), Green architecture and compatible with the Egyptian environment.. The paper concludes with a set of general findings and recommendations that can be used to extract the most important items of the green building assessment in Egypt, which must be considered to reach buildings that are compatible with the environmental sustainability standards and the Egyptian local environment.
\end{abstract}

Keywords: Green Building Assessment Systems - Proposed System GBS - Assessment of Environmental Sustainability of Traditional and Contemporary Buildings in Egypt 
تقييم الاستدامة البيئية للمباني التقليدية والمعاصرة في مصر

فى ضوء التحليل المقارن لأنظمة تقييم العمارة الخضراء

أ.د محمـدعزي أحمد1, أ.د. أشرف أبو العيون عبد الرحيم², م. رشـا ماهر عبد الوهـاب3

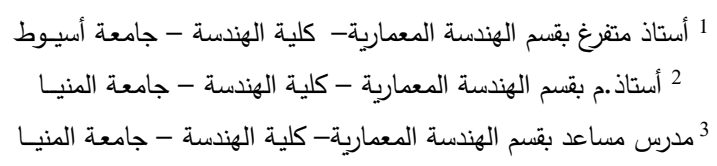

بما يجب أن تكون عليه أدوات التقييم العالمية أو المحلية ويمكن من

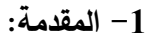

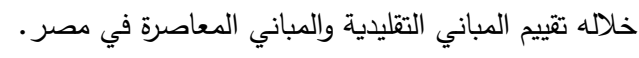

1-2-1الهفف من الدراسة:

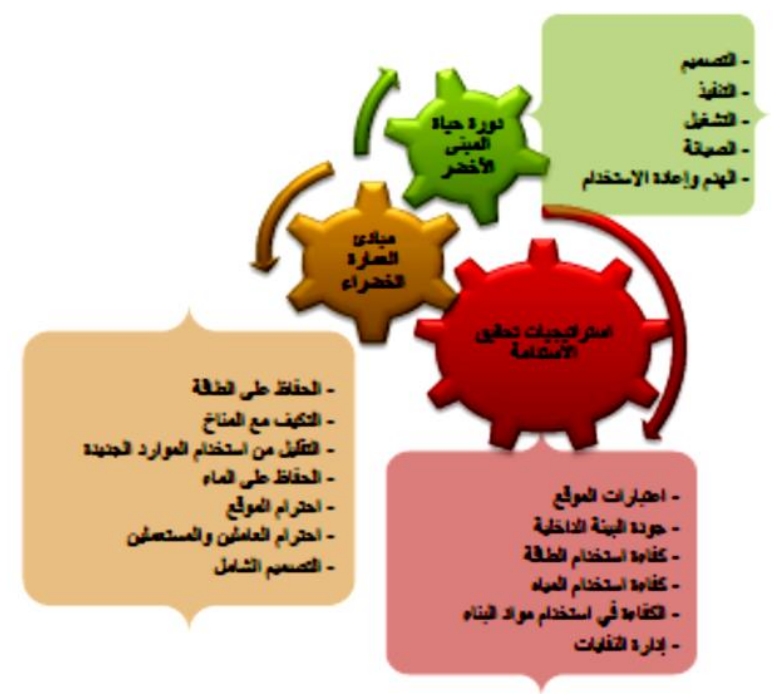

شكل رقم (1) استراتيجيات ومعايير تقييم (ستدامة المبنى الأخضرمن عمل

لباحثة

1-1-1 الفرضية البشثية:

يمكن تحديد الفؤضية البحثية بما يحقق كل مما يأتى:• إمكانية صياغة نظام لتقييم المباني الخضراء التقليدية والمعاصرة في مصر بما يراعي الظروف البيئية المحلية

باستخدام التحليل المقارن لأنظمة تقييم مشابهة.

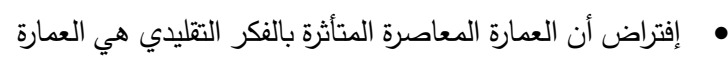

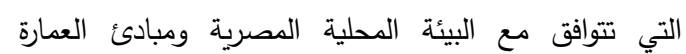

الخضراء.

1-4-1 المنهية البشية:

اعتمد البحث على المنهجية التالية:

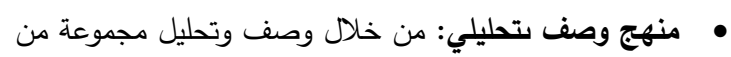

أنظمة التتييم العالمية والمحلية التي تم اختيارها من دول مشابهة وصنايل

لمصر
تلعب معايير الاستدامة البيئية والمنتجات الخضراء دوراً

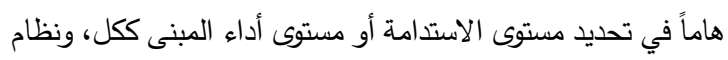

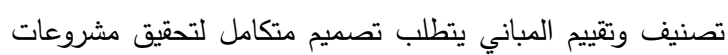
مسئولة بيئياً وذات كفاءة في استخدام الطاقة والمياه والمواد المختلفة

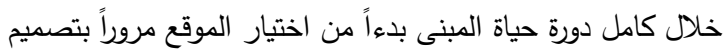
المبنى وتثغيله وصيانته ثم تجديده ثم في النهاية هدمه (1).

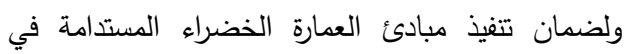

المباني وذلك من خلال مجموعة من الأدوات، ولتأكيد ما إذا كان الفيان

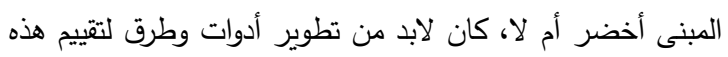

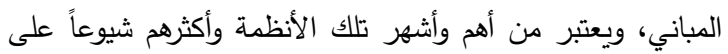

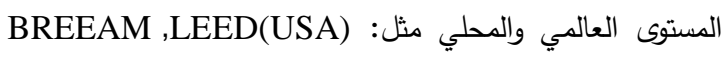
،GPRS (Egypt) ,ESTIDAMA (abu dhabi)،(UK) والتي يتم المقارنة بينهم والتعرف على مدى التوافق والاختلاف، اللوصول لتتييم العمارة التقليدية والمعاصرة في منطقة الدراسة. 1-1-1 المشكلة البحثة: ظهرت العديد من نظم تقييم المباني التي تتناول تقييم

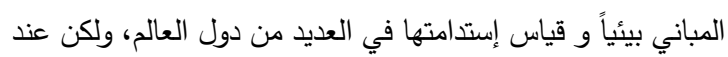
تطبيق هذه المقاييس فى دول أخرى ظهرت العديد من العقبات، وقد

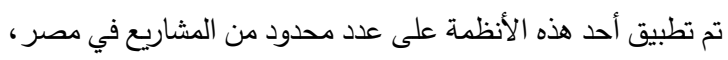

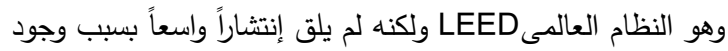

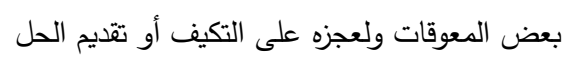
الأمثل للظروف المحلية، ثم ظهر فى مصر أسوة بدول كثيرة في الكي العالم أنظمة تتييم تختص بتقييم المباني الخضراء مثل نظام الهرم الأخضر الذي أصدره المركز القومي لبحوث الإسكان والبناء ونظام النطان ترشيد، ولكن لم يتم انتشارهما وتفعيلهما.

لذا فإن المثكلة البحثية تتمثل فى عدم ملاءمة أنظمة

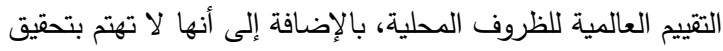

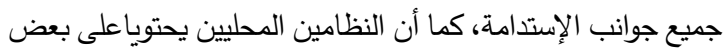

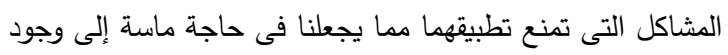
نظام تقييم مصري يراعي إيجابيات وسلبيات الأنظمة الأخرى مقارنة 
Leadership in Energy and Environmental)

(Design والذى تم البدء في تطبيقه عام2000م.

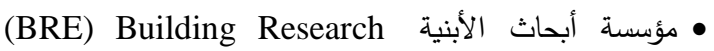

.Establishment

• الجمعية الأمريكية لمهندسي التدفئة والتبريد وتكييف الهواء

(ASHARE)

• مجلس الإمارات للأبنية الخضراء (EGBC) الذي عدل في نظام

الريادة في الطاقة والتصميم البيئي (LEED)

لتعدد أنظمة التقييم المباني العالمية والمحلية كان لزاماً

البحث عن أسس في اختيار الأنظمة التي يتم من خلالها عمل

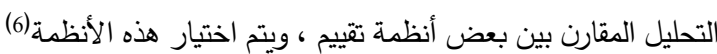

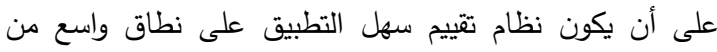

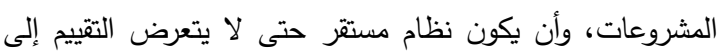

تغيير جذري، وأن يكون نظام منتشر وتم تطبيقه في العديد من

المباني.

وتتحصر نظم تقييم العمارة الخضراء المختارة للمقارنة

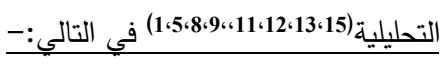

•

$$
\text { البيئي لمؤسسة بحوث البناء الاتجليزي. }
$$

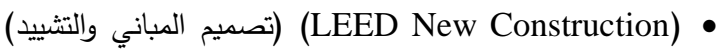
الإصدار الرابع نظام التصنيف الأكثر استخداماً على مستوى العين

العالم.

• نظام تقييم درجات اللؤلؤمRS) ESTIDAMA) :-تم تطوير

$$
\text { نظام التقييم في إلإمارات العربية المتحدة. }
$$

• نظام تقييم الهرم الأخضر (GPRS) : نظام تقييم المباني الخضراء

في مصر ، تم تطويره من قبل المركز القومي للبحوث للإسكان

$$
\text { والبناء. }
$$

1-2 -1-2 مقارنة بين أنظمة التقييم من حيث عدد (مجالات التقييم)

\section{نقاط (التقييم، والمستويات):}

من خلال المقارنة التى تمت في هذا المجال وما تم

الإنتهاء اليه من بيانات يمكن توضيحها بالجدول المرفق رقم (1)والذى يتضمن تحليلاً كمياً لأقصى درجة ممكنة من نقاط التقييم

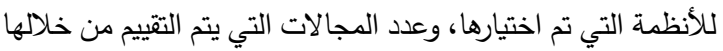

وعدد البنود الفرعية، وعدد مستويات التقييم للأنظمة المختلفة.
يتناول البحث عرض وتحليل لأنظمة تقييم إستدامة المباني الأشهر عالمياً مثل BEREEAMو والنظام الإمارتي ESTIDAMA والنظام المصري GPRS بهدف الوصول إلى أفضل مجالات التقييم التى يمكن تواجدها بنظام التقييم البيئي المحلي بحيث

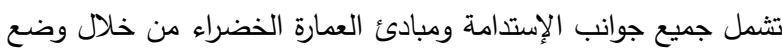
مجموعة من المعاييرواستراتيجيات تقييم استدامة المباني للوصول للمبنى

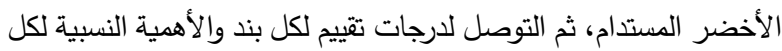
منهم، لتقييم المباني التقليدية والمعاصرة في مصر ، والتي يمكن من خلالها الحكم على المباني وتصميم وتنفيذ مباني أكثر استدامة والتي تتمثل

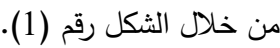
كما يهدف البحث لتقييم العمارة التقليدية والمعاصرة في مصر من خلال اختيار نماذج لمباني ممثلة لهما للوصول لنوعية العمارة المتوافقة

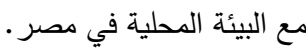

• منهج المنهج التحليلي المقارن: بعمل دراسة مقارنة لأنظمة التقييم المختارة وصولاً لأهم مجالات التقييم الواجب توافرها بنظام التقييم المحلى من خلال الجد او لو يثمل جميع استراتيجيات الاستدامة ومبادئ العمارة الخضراء. • المنهج الاستتتاجي:بمحاولة الوصول إلى نظام يمكن استخدامه في تقييم المباني الخضراء التقليدية والمعاصرة في الاستياجي مصر واستنتاج نقاط التقييم والأهمية النسبية لكل بند من بنود التقييم من خلال الجداول والرسومات البيانية. • المنهج التحليلي الاستنتاجي: من خلال تقييم العمارة التقليدية والمعاصرة في مصر من خلال نماذج بنائية ممثلة. 2- أنظمة تقييم المباني الخضراء المختارة: تعتبر أنظمة تصنيف وتقييم المباني في تطور وتغي رمستمر لذلك فمن الضروري متابعة هذه التطورات بهدف معرفة المتطلبات والاحتياجات الجديدة للوصول بالمبنى لمستويات أعلى من الاستدامة

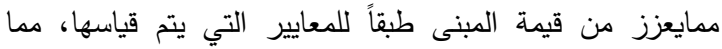
يستوجب ضرورة وجود معايير تقييم ومراقبة تصميم وتثييد وتشغيل

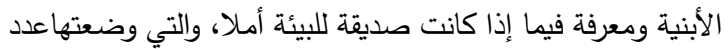

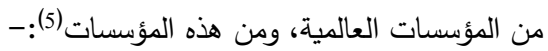

\begin{tabular}{|c|c|c|c|c|}
\hline GPRS2011 & $\begin{array}{c}\text { PRS for } \\
\text { ESTIDAMA } \\
\end{array}$ & LEEDv4 & BREEAM 2014 & مجالات المقارنة \\
\hline 180 & 180 & 110 & 119 & إجمالي النقاط \\
\hline 7 & 7 & 8 & 10 & عدد مجالات التقييم الرئيسية \\
\hline 70 & 86 & 67 & 107 & البنود الفرعية \\
\hline 4 مستويات & 5 مستويات & 4 مستويات & 5 مستويات & مستويات نتائج التسجيل \\
\hline 5 سنو ات & - & (5 5 سنوات & حتى المرحلة المقبلة & صلاحية \\
\hline
\end{tabular}
• المجلس الأمريكي للأبنية الخضراء (USGBC) الذي وضع

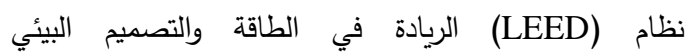

جدول (1) توزيع عدد مجالات التقييم، نقاط التقييم، ومستويات التقييم(5)،(6)،(11): 
-2- مقارنة بين أنظمة التقييم من حيث النسب المئوية للتقييم: من خلال مقارنة البرامج السابقة يمكن ملاحظة التنوع بين

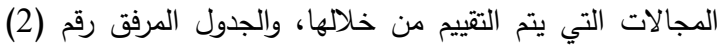

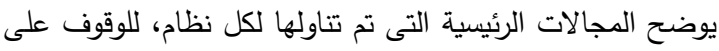

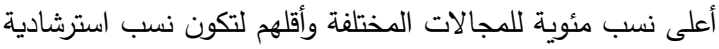
اللتوصل إلى نظام مقترح من قبل البحث.
ووفقًا للجدول رقم (1)، يحتوي BREEAM على أكبر عدد

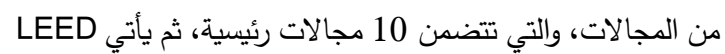

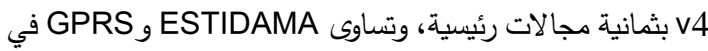
المجالات الرئيسيةحيث تضمنا سبعة مجالات ولكن اختلفي النت البنود الفرعية حيث احتوى استدامة على عدد86 بند في حين الهرم الأخضر يحتوي على عدد 70 بند.

جدول (2) مقارنة بين مجالات التقييم للأنظمة السابقة(13،13،11):

\begin{tabular}{|c|c|c|c|c|}
\hline GPRS2011 & $\begin{array}{c}\text { PRS fo } \\
\text { ESTIDAMA }\end{array}$ & LEED v4 & BREEAM 2014 & نظام تصنيف البناء الأخضر \\
\hline$\% 10$ & $\% 7$ & & $\% 12$ & الإدارة \\
\hline$\% 15$ & $\% 15$ & $\% 26$ & $\% 10$ & إختيار الموقع \\
\hline$\% 30$ & $\% 24$ & $\% 10$ & $\% 6$ & المياه \\
\hline$\% 25$ & $\% 25$ & $\% 35$ & $\% 19$ & الطاقة \\
\hline$\% 10$ & $\% 16$ & $\% 14$ & $\% 12.5$ & المواد والمخلفات \\
\hline$\% 10$ & $\% 13$ & $\% 15$ & $\% 15$ & جودة البيئة الداخلية \\
\hline- & - & - & $\% 8$ & الأولوية الإقليمبة \\
\hline- & - & - & $\% 7.5$ & المخلفات \\
\hline- & - & - & $\% 10$ & التلوث \\
\hline$(10+)$ & $(3+)$ & $(10+)$ & $(10+)$ & الإبداع \\
\hline
\end{tabular}

استتباط التقييم المقترح للدراسة، ومن خلال الجدول التالي رقم (3) يتم إعادة توزيع نقاط تقييم البنود الفرعية للأنظمة التي تم اختيارها في التحليل المقارن من خلال 6 مجالات رئيسية طبقاً لمعايير

واستراتيجيات الإستدامة البيئية ووفقاً لمبادئ العمارة الخضراء.
ومن خلال التحليل المقارن السابق لأنظمة التقييم

المختلفة نجد أن تحديد النسب الئوية للبنود المختلفة تختلف تبعاً للظروف المحلية والبيئية لكل دولة، ولاستتتاج مقترح تقييم جديد لنظام الهرم الأخضر ، يتم عمل مقارنة تحليلية للنظم السابقة، وحتى يسهل

جدول (3) مقارنة بين مجالات التقييم للأنظمة بعد إعادة توزيع النقاط:

\begin{tabular}{|c|c|c|c|c|c|c|c|c|}
\hline \multicolumn{2}{|c|}{ GPRS2011 } & \multicolumn{2}{|c|}{$\begin{array}{c}\text { PRS for } \\
\text { ESTIDAMA } \\
\end{array}$} & \multicolumn{2}{|c|}{ LEED v4 2014} & \multicolumn{2}{|c|}{ BREEAM 2014} & مجالات التقييم الرئيسية \\
\hline $7 \%$ & 11 & $19 \%$ & 34 & $26 \%$ & 26 & $28 \%$ & 31 & الموقع \\
\hline $31 \%$ & 53 & $22 \%$ & 39 & $10 \%$ & 10 & $9 \%$ & 10 & المياه \\
\hline $26 \%$ & 45 & $26 \%$ & 46 & $35 \%$ & 35 & $28 \%$ & 30 & الطاقة \\
\hline $18 \%$ & 31 & $15 \%$ & 26 & $15 \%$ & 15 & $18 \%$ & 19 & جودة البيئة الداخلية \\
\hline $6 \%$ & 10 & $7 \%$ & 13 & $5 \%$ & 5 & $10 \%$ & 11 & المواد \\
\hline $12 \%$ & 20 & $11 \%$ & 19 & $9 \%$ & 9 & $7 \%$ & 8 & المخلفات \\
\hline $6 \%$ & +10 & $\% 2$ & +3 & $\% 10$ & +10 & $\% 9$ & +10 & الإبداع والابتكار في التصميم \\
\hline$\% 100$ & 170 & $100 \%$ & 177 & $\% 100$ & 100 & $\% 100$ & 109 & المجموع (باستثناء الابتكار) \\
\hline
\end{tabular}

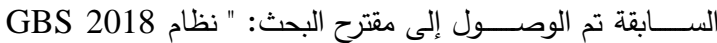

."Green Building System"

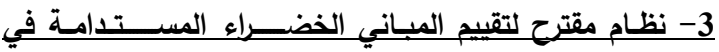
Green Sustainble Building Assessment مصـــ :System In Egypt

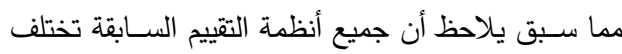

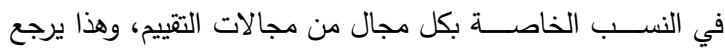

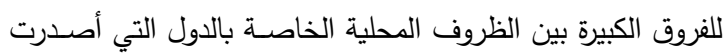

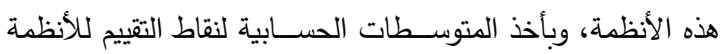


3-3-3 البنود الإلزامية (R) لنظام التقييم المقترح: من خلال التحليل المقارن للأنظمة التي تم اختيارها نجد أن هناك بعض البنود الإلزامية التي يجب تحقيقها بالمبنى أولاً ليتم إخضـاعه لتقييم المباني الخضـراء، ومن خلال الجدول رقم (4) يتم عرض أهم البنود الإلزامية التي تم التوصل إلتيهل إليها من خلاد التحليل

$$
\text { المقارن للأتظمة التي تم اختيارها. }
$$

من خلال المقارنة التحليلية للأنظمة السـابقة تم التوصـل

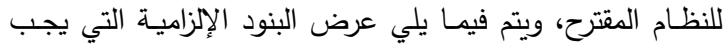

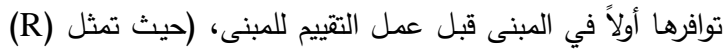
البنود الإلزاميـة)، ثم عرض للبنود الفرعيـة ونقـاط التقييم والأوزان

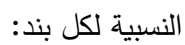

جدول (4) البنود الإلزامية (R) لنظام التقييم المقترح:

\begin{tabular}{|c|c|}
\hline بنودالتقبيم الإلزامية & مجالات التقييم \\
\hline 1-م-1 تصميم الأنظمة الطبيعية و استر اتيجيات الإدارة & \multirow{3}{*}{ 1- احتر امخصائصالموقع } \\
\hline 1-2-2 منع التلوث الناجم عن الأعمال الإنشائية & \\
\hline 1-م-3 التنسيق الجيد للموقع & \\
\hline 2-م-1 كفاءة استخدام المياه في الأماكن الخارجية & \multirow{2}{*}{ 2- اكفاءةقفياستخدام المياه } \\
\hline 2-م-2 تو افر عدادات لقياس استهلاك المياه بالمبنى & \\
\hline 3-م-1 كفاءة استهلاك الطاقة من خلال تصميم المبنى & \multirow{3}{*}{ 3- الكفاءة في استخدام الطاقة } \\
\hline 3-م-2 دعم المبنى بعدادات قياس الطاقة & \\
\hline 3-م-3 القضاءعلى مركبات الكلوروفلوروكربون & \\
\hline 4-م-1 تحقيق الحد الأدنى لجودة الهو اء الداخلى & \multirow{3}{*}{ 4- الجودة في البيئة الداخلية } \\
\hline 4-2-2 التحكم البيئى فى دخان التبغ ETS & \\
\hline ? منع ومكافحة الملوثات و الميكروبات و البكتريا فى الاماكن المغلقة & \\
\hline 5-م-1 الحد من استعمال المو اد ذات التأثير السلبى والخطرة & 5- الكفاءة في استخدام مواد البناء \\
\hline الإدارة السليمة للمخلفات & 6- الكفاءة في إدارة المخلفات \\
\hline
\end{tabular}

الاستدامة، ويتم تقييم كل مجال رئيسي من خلال بنود فرعية والتي تم وضــــها من خلال التحليل المقارن للأنظمة التي تم اختيارها والتي تمثل مبادئ العمارة الخضــراء، ويمثل الجدول التالي رقم (5)

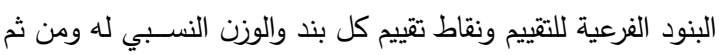
إجمالي نقاط التقييم لكل مجال رئيسي للتقييم والوزن النسبي له. له.
2-2-3 توزيع نقاط التقييم والأونان النسـيبة للمجالات الرئيسـية والبنود الفرعية لنظام التقييم المقترح: وبعد تحقيق البنود الإزامية السابقة بالمبنى، يتم التقييم من

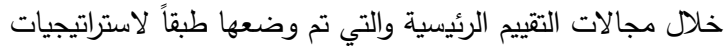

جدول (5) البنود الفرعية لنظام التقييم المقترح:

\begin{tabular}{|c|c|c|c|c|c|c|}
\hline \multicolumn{2}{|c|}{ قيمة|التقييم } & \multicolumn{5}{|c|}{ مجالات التقيبم الرئيسية والفرعية } \\
\hline الوزن النسبي & النقاط & البنود - اد & 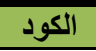 & الفئة & & \\
\hline $1.6 \%$ & 2.5 & اختيار المو اقع ذات الأولوية & 1-1-1 & \multirow{2}{*}{ اختيار الموقع } & \multirow{2}{*}{$1-1$} & \\
\hline $1 \%$ & 1.5 & تقييم الموقع ومر اعاة التتمية الحضرية & $1-1-2$ & & & \\
\hline $0.7 \%$ & 1 & تطوير الجواروتوفر البنية التحتية بالمنطقة & 1-2-1 & \multirow{7}{*}{ علاقة المبنى بالبيئة المحيطة } & \multirow{7}{*}{$1-2$} & \\
\hline $0.7 \%$ & 1 & إعادة تطوير و إحياء المو اقع المتضررة & $1-2-2$ & & & \\
\hline $0.7 \%$ & 1 & القرب من وسائل الترفيه و الخدمات & 1-2-3 & & & \\
\hline $1.34 \%$ & 2 & حماية الحياه الطبيعية & $1-2-4$ & & & \\
\hline $0.7 \%$ & 1 & دعم الجوانب الاجتماعية & 1-2-5 & & & \\
\hline $0.7 \%$ & 1 & دعم الجو انب الاقتصادية & 1-2-6 & & & \\
\hline $0.7 \%$ & 1 & دعم الجو انب التر اثية و الثقافية & 1-2-7 & & & \\
\hline $1.6 \%$ & 2.5 & تصميم الأنظمة الطبيعية & 1-3-1 & \multirow{3}{*}{ جودةةعملية/لانشاء } & \multirow{3}{*}{$1-3$} & \\
\hline $1.6 \%$ & $\mathrm{R}+2.5$ & منع التلوث الناجم عن الأعمال الإنشائية & 1-3-2 & & & \\
\hline $0.7 \%$ & $\mathrm{R}+1$ & استر اتجيات الإدارة المسئولة عن البيئة & 1-3-3 & & & \\
\hline $2.0 \%$ & 3 & استخدام وسائل النقل العام & 1-4-1 & استخدام وسائل النقل البذيلة & $1-4$ & \\
\hline
\end{tabular}




\begin{tabular}{|c|c|c|c|c|c|c|}
\hline \multicolumn{2}{|c|}{ قيمة|التقييم } & \multicolumn{5}{|c|}{ مجالات التقييم الرئيسية والفرعية } \\
\hline الوزن النسبي & النقاط & البنود & الكود & الفئة & & \\
\hline $1 \%$ & 1.5 & تشجيع استخدام الدراجات & $1-4-2$ & & & \\
\hline $1 \%$ & 1.5 & تو افر أماكن انتظار السيارات الخاصة & 1-4-3 & & & \\
\hline $1 \%$ & 1.5 & التنسيق الجيد للموقع & $1-5-1$ & \multirow{3}{*}{ تصميم وتخطيط الموقع } & \multirow{3}{*}{$1-5$} & \\
\hline $1 \%$ & 1.5 & حماية|المشاة & $1-5-2$ & & & \\
\hline $0.7 \%$ & 1 & تسهيلات لذوى الاحتياجات الخاصة & $1-5-3$ & & & \\
\hline $1.34 \%$ & 2 & التحكم الكمى و التحكم النوعى & $1-6$ & إدارةمياه الأمطار & $1-6$ & \\
\hline $1.34 \%$ & 2 & للمناطق المكثوفة والمناطق المغطاه & $1-7$ & الجزر الحرارية & $1-7$ & \\
\hline 0.7 & 1 & تقليل التلوث الضوئي & $1-8$ & تقليل التلوث الضوئي & $1-8$ & \\
\hline$\% 22$ & 33 & \multicolumn{5}{|c|}{ إجمالى تقييم البند } \\
\hline $6 \%$ & 9 & كفاءة استخدام المياه في الأماكن الخارجية & 2-1-1 & \multirow{2}{*}{ الترشيد فى استهلاك المياه } & \multirow{2}{*}{ 2-1 } & \multirow{6}{*}{ 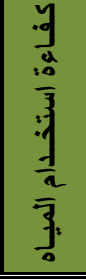 } \\
\hline $5 \%$ & 7 & كفاءة استخدام المياه في الأماكن المغلقة & $2-1-2$ & & & \\
\hline $1 \%$ & 1.5 & تقليل استخدام مياه الثرب في ري المناطق الخارجية & 2-2-1 & \multirow{3}{*}{ مراقبة استهلاك المياه } & \multirow{3}{*}{ 2-2 } & \\
\hline $2 \%$ & 3 & منع تلوث وتسرب مصادر المياه & 2-2-2 & & & \\
\hline $1 \%$ & $\mathrm{R}+1.5$ & تو افر عدادات لقياس استهلالك المباه بالمبنى & $2-2-3$ & & & \\
\hline $3 \%$ & 5 & معالجة المياه الرمادية و إعادة استخدامها & $2-3$ & التذوير وإعادة استخدام المياه & $2-3$ & \\
\hline$\% 18$ & 27 & \multicolumn{5}{|c|}{ إجمالى تقييم البند } \\
\hline $7 \%$ & 10 & الحد الأدنى من استهلاك الطاقة & 3-1-1 & \multirow{4}{*}{ ترشيد استهلاك الطاقة } & \multirow{4}{*}{ 3-1 } & \multirow{5}{*}{ 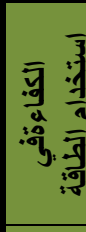 } \\
\hline $4.6 \%$ & 7 & كفاءة استهلاك الطاقة فى التجهيز ات & 3-1-2 & & & \\
\hline $4.6 \%$ & 7 & تحقيق منطلبات العزل و الكفاءة & 3-1-3 & & & \\
\hline $0.7 \%$ & 1 & التحكم الفردي فى الأنظمة داخل المبنى & $3-1-4$ & & & \\
\hline $5.3 \%$ & 8 & تثجيع استخدامالطاقة|لمتجددة & 3-2 & توظيف مصادر الطاقةة المتجددة & 3-2 & \\
\hline 0.7 & $\mathrm{R}+1$ & دعمالمبنبعدادات قياس الطاقة & 3-3-1 & \multirow{3}{*}{ رصد مراقبة آداء المبنى } & \multirow{3}{*}{ 3-3 } & \\
\hline $1.4 \%$ & 2 & تقليل الأحمال الحرارية من أنظمة الإضاءة و التكييف & 3-3-2 & & & \\
\hline $0.7 \%$ & 1 & عمليات التنغيل و الصيانة وخطة للطو ارئ & 3-3-3 & & & \\
\hline $1.65 \%$ & 2.5 & تقليل انبعاثات أكاسيد الكربون & $3-4-1$ & \multirow{2}{*}{ القضاء الملوثات الهوائية } & \multirow{2}{*}{$3-4$} & \\
\hline $1 \%$ & $\mathrm{R}+1.5$ & القضاء على مركبات الكلوروفلوروكربون & 3-4-2 & & & \\
\hline$\% 27$ & 41 & \multicolumn{5}{|c|}{ إجمالى تقييم البند } \\
\hline
\end{tabular}

تابع جدول (5) البنود الفرعية لنظام التقييم المقترح:

\begin{tabular}{|c|c|c|c|c|c|c|}
\hline \multicolumn{2}{|c|}{ قيمة|التقييم } & \multicolumn{5}{|c|}{ مجالات التقبيم الرئيسبة والقرعية } \\
\hline الوزن النسبي & النقاط & 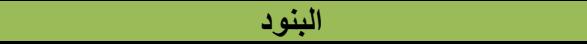 & الكود - lل الكو & الفئة & & \\
\hline $1.36 \%$ & 2 & تحقيق الحد الأدنى لجودة الهو اء الداخلى & 4-1-1 & \multirow{3}{*}{ تزويد المباني بمستويات مناسبة الطبية } & \multirow{3}{*}{ 4-1 } & \multirow{13}{*}{ 亨: } \\
\hline $0.68 \%$ & 1 & تحسين عملية التهوية & 4-1-2 & & & \\
\hline $0.68 \%$ & 1 & إعداد برامج الإدارة البيئية وتقيييم لجودة الهو اء الداخلى & 4-1-3 & & & \\
\hline $1 \%$ & 1.5 & مو اد لاصقة & 4-2-1 & \multirow{5}{*}{ منع التشطييات التى تلوث } & \multirow{5}{*}{ 4-2 } & \\
\hline $1 \%$ & 1.5 & 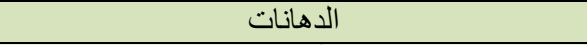 & 4-2-2 & & & \\
\hline $0.68 \%$ & 1 & السجاد و الأرضيات الصلبة & 4-2-3 & & & \\
\hline $0.68 \%$ & 1 & أنظمة السقق & 4-2-4 & & & \\
\hline $0.68 \%$ & 1 & خفض الفورمالديهيد & $4-2-5$ & & & \\
\hline $1 \%$ & 1.5 & توفير الإضـاءة الطبيعية والمطلات & 4-3-1 & \multirow{2}{*}{ تحقيق الراحة البصرية } & \multirow{2}{*}{$4-3$} & \\
\hline $1 \%$ & 1.5 & التحكم فى مستويات الاضـاءة الداخلية & 4-3-2 & & & \\
\hline$\% 3$ & 4.5 & تحقبقالر احة|الحر ارية & 4-4 & تحقيق الراحة الحرارية & 4-4 & \\
\hline$\% 0.68$ & 1 & تحقيق الراحة الصوتية & $4-5$ & تحقيق الراحة الصوتية & $4-5$ & \\
\hline$\% 0.68$ & 1 & توفير الأمن و الأمان & 4-6 & تحقيق الأمن والأمان & 4-6 & \\
\hline $1 \%$ & 1.5 & مشاركة أصحاب المصلحة & $4-7-1$ & تحقيق جودة التصميم الإخلي & 4-7 & \\
\hline
\end{tabular}


Journal of Advanced Engineering Technology (JAET), Vol. 39, No. 1. January 2020

\begin{tabular}{|c|c|c|c|c|c|c|}
\hline \multicolumn{2}{|c|}{ قيمة|التقييم } & \multicolumn{5}{|c|}{ مجالات التقييم الرئيسية والفرعية } \\
\hline الوزن النسبي & 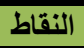 & 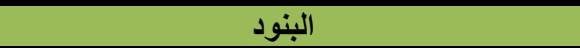 & 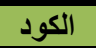 & \multicolumn{3}{|l|}{ الفئة } \\
\hline $1 \%$ & 1.5 & دليل مستخدم البناء & 4-7-2 & & & \\
\hline $1 \%$ & 1.5 & تسهيل الصيانة & 4-7-3 & & & \\
\hline $0.68 \%$ & 1 & الاتصالات المستدامة & 4-7-4 & & & \\
\hline$\% 17$ & 25 & \multicolumn{5}{|c|}{ إجمال تثقييم البند } \\
\hline$\% 0.64$ & 1 & الاستفادة من المو اد المحلية لتنمية الاقتصاد المحلي & $5-1$ & الاستفادة من المواد المحلية & $5-1$ & \multirow{9}{*}{ 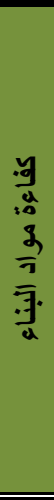 } \\
\hline$\% 0.64$ & 1 & مو اد مصنعة بالموقع & $5-2-1$ & \multirow{6}{*}{ اختيارمواصفات موادالبناء } & \multirow{6}{*}{$5-2$} & \\
\hline$\% 1.28$ & 2 & مو اد متجددة بسهولة & $5-2-2$ & & & \\
\hline$\% 0.64$ & 1 & مو ادخفيفةالوزن & $5-2-3$ & & & \\
\hline$\% 0.64$ & 1 & اختبار ات متانة مو اد الإنشاء & $5-2-4$ & & & \\
\hline$\% 0.64$ & 1 & 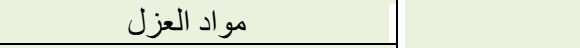 & $5-2-5$ & & & \\
\hline$\% 0.64$ & 1 & 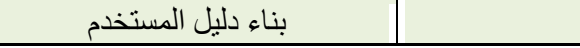 & $5-2-6$ & & & \\
\hline $0.96 \%$ & 1.5 & تقليل تأثيروتكلفة دورة حياة المبنى & $5-3$ & التكلفة والاقتصاد & $5-3$ & \\
\hline$\% 0.64$ & 1 & الحد من استعمال المو اد ذات التأثثير السلبى والخطرة & $5-4$ & الحد من استعمال المواد الخطرة & $5-4$ & \\
\hline$\% 7$ & 11 & \multicolumn{5}{|c|}{ إجمالى تقييم البند } \\
\hline$\% 1.4$ & $\mathrm{R}+2$ & الإدارة السليمة للمخلفات & 6-1-1 & \multirow{2}{*}{ الترشيد في الاستهلاك } & \multirow{2}{*}{ 6-1 } & \multirow{6}{*}{$\frac{\overline{3}}{3}$} \\
\hline $0.7 \%$ & 1 & تقليل حجم المخلفات الناتجة عن عمليات التشييد & 6-1-2 & & & \\
\hline $0.7 \%$ & 1 & إعادة تأهيل المباني القائمة & 6-2-1 & \multirow{2}{*}{ إعادة الاستخدام } & \multirow{2}{*}{$6-2$} & \\
\hline $2.8 \%$ & 4 & إعادة استخدام مواد البناء & 6-2-2 & & & \\
\hline$\% 2.1$ & 3 & تخزين وتجميع المواد القابلة للتدوير & 6-3-1 & \multirow{2}{*}{ إعادة التدوير } & \multirow{2}{*}{$6-3$} & \\
\hline$\% 1.4$ & 2 & ابتكار مواد ومنتجات البناء المعاد تدويرها & $6-3-2$ & & & \\
\hline$\% 9$ & 13 & \multicolumn{5}{|c|}{ إجمالى تقييم البند } \\
\hline- & 4 & الإبداع التصميمى أو الإنشائى & $7-1$ & الإبداع التصميمى أو الإنثائى & $7-1$ & \multirow{3}{*}{$\frac{3}{a}$} \\
\hline- & 4 & الأولوية الجغر افية & $7-2$ & الأولوية الجغرافية & $7-2$ & \\
\hline- & 2 & تفويض مختصين محترفين من البرنامج & $7-3$ & تفويض مختصين محترفين & $7-3$ & \\
\hline \multicolumn{2}{|c|}{ + 10للإبداع والابتكار } & \multicolumn{5}{|c|}{ إجمالى تقييم البند } \\
\hline $100 \%$ & 150 & \multicolumn{5}{|c|}{ إجمالى التقييم } \\
\hline
\end{tabular}

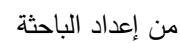

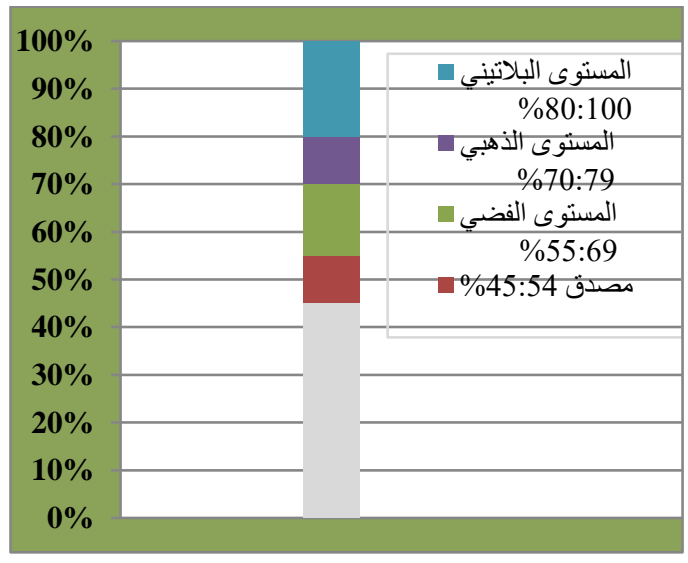

شكلرقم (3) مستويات التقييم بالنظام المقترح من إعداد الباحثة
3-3-3 مستويات التقييم لنظام التقييم المقترح:

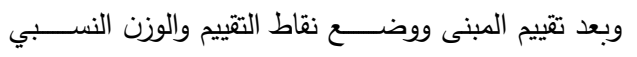

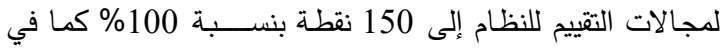
الجدول السـابق (5)، ومن ثم يتم تصــنيف المبنى لمســتوى تقييم طبقاً لإجنالي النقاط، ويتم تصنيف المستويات إلى 4 مستويات تبدأ

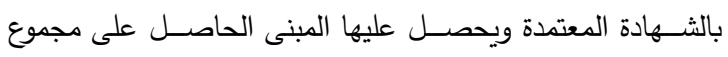
نقاط من 65: 79 نقطة، ثم المستوى الفضي للمبنى الحاصل على

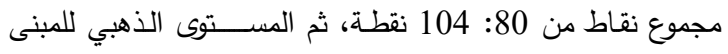
الحاصــل على مجموع نقاط من 105: 119 نقطة، ثم المســـتوى البلاتيني (الأخضـر )للمبنى الحاصل على نعلى مجموع نقاط من 120:

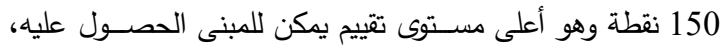
ويمثل الجدول التالي (6) والثـكل المرفق رقم (3)مسـتويات التقييم المختلفة للنظام المقترح. 
جدول (6) مستويات التقييم لنظام التقييم المقترح:

\begin{tabular}{|c|c|c|}
\hline \multicolumn{3}{|c|}{ مستويات التقيبم المختلفة } \\
\hline $45: 54 \%$ & $65-79$ & شهادة معتمدة \\
\hline $55: 69 \%$ & $80-104$ & المستوى الفضي \\
\hline $70: 79 \%$ & $105: 119$ & المستوى الذهبي \\
\hline $80: 100 \%$ & $120-150$ & المستوى البلاتيني (الأخضر) \\
\hline
\end{tabular}

من إعداد الباحثة

يمكن عرض مجالات التقييم للنظام المقترح من خلال

الثكل المرفق رقم (2) أهم المجالات الرئيسة للنظام المقترح والتي عردالي

ومن خلال التحليل السابق لنظام التقييم المقترح للمباني

تم وضعها طبقاً لاستراتيجيات الاستدامة، كما يمثل شكل رقم (4)

الخضراء المستدامة في مصر يمكن تلخيص المجالات الرئيسية

الأوزان النسبية لكل مجال رئيسي لنظام التقييم المقترح.

والأوزان النسبية لها ومستويات التقييم في الأشكال التالية:

3- 5- ملخص مجالات تقييم والنسب المئوية للنظام المقترح

لتقييم المباني الخضراء المستدامة في مصر :

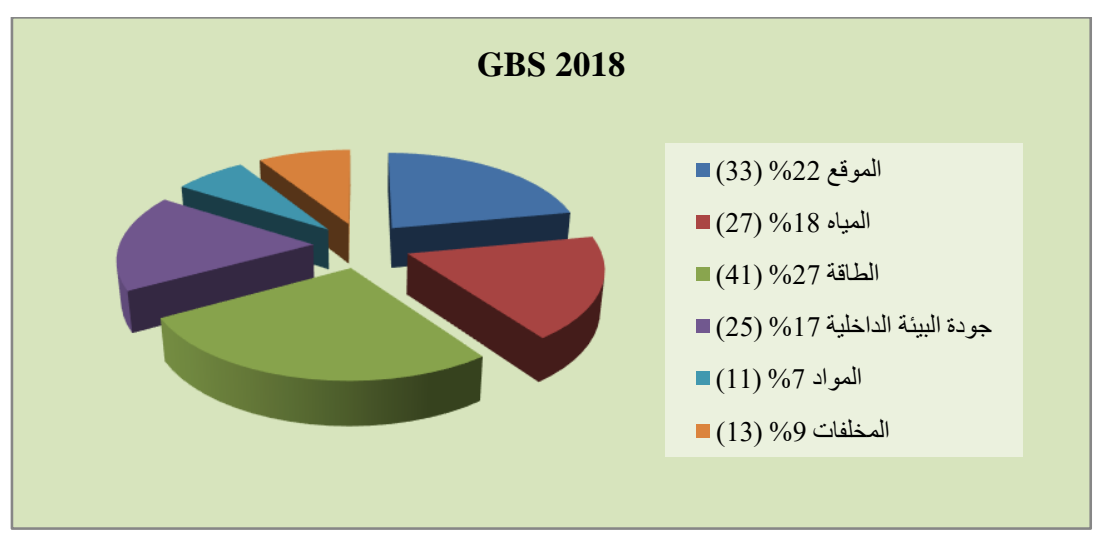

من إعداد الباحثة
شكلرقم (4) توزيعا لأوزان النسبية على مجالات التقييم في النظام المقترح

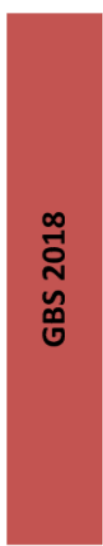

من إعداد الباحثة

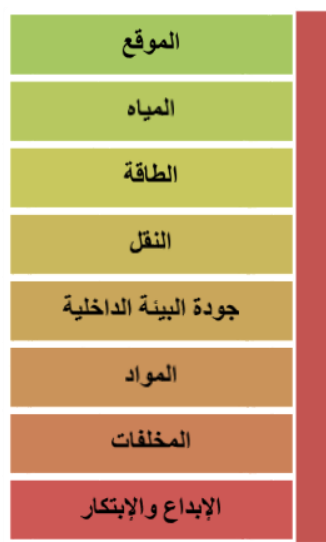

شكلرقم (2) مجالات التقييم بنظام
Green Building System حيث تمثل الحروف اختصار له

$$
\text { وسنة } 2018 \text { هي السنة التي وُضع بها النظام. }
$$

GBS ) وفيما يلي مقارنة بين المجالات الرئيسية للنظام المقترح

2018) والأنظمة التي تم اختيارها كما بالجدول التالي رقم (4):

جدول (4) مقارنة بين المجالات الرئيسية للنظام المقترح والأنظمة المختلفة:

\begin{tabular}{|c|c|c|c|c|c|c|c|c|c|c|}
\hline \multicolumn{2}{|c|}{$\begin{array}{l}\text { GBS } \\
2018 \\
\end{array}$} & \multicolumn{2}{|c|}{$\begin{array}{l}\text { GPRS } \\
2011 \\
\end{array}$} & \multicolumn{2}{|c|}{$\begin{array}{c}\text { PRS for } \\
\text { ESTIDAMAv1.0 }\end{array}$} & \multicolumn{2}{|c|}{$\begin{array}{c}\text { LEED v4 } \\
\text { BD+C2014 } \\
\end{array}$} & \multicolumn{2}{|c|}{$\begin{array}{l}\text { BREEAM } \\
\text { UK } 2014 \\
\end{array}$} & \multirow{2}{*}{ مجالات التقييم الرئيسية } \\
\hline $22 \%$ & 33 & $7 \%$ & 11 & $19 \%$ & 34 & $26 \%$ & 26 & $28 \%$ & 31 & \\
\hline $18 \%$ & 27 & $31 \%$ & 53 & $22 \%$ & 39 & $10 \%$ & 10 & $9 \%$ & 10 & المياه \\
\hline $27 \%$ & 41 & $26 \%$ & 45 & $26 \%$ & 46 & $35 \%$ & 35 & $28 \%$ & 30 & الطاقة \\
\hline $17 \%$ & 25 & $18 \%$ & 31 & $15 \%$ & 26 & $15 \%$ & 15 & $18 \%$ & 19 & جودة البيئة الداخلية \\
\hline $7 \%$ & 11 & $6 \%$ & 10 & $7 \%$ & 13 & $5 \%$ & 5 & $10 \%$ & 11 & المواد المو \\
\hline $9 \%$ & 13 & $12 \%$ & 20 & $11 \%$ & 19 & $9 \%$ & 9 & $7 \%$ & 8 & المخلفات \\
\hline $7 \%$ & +10 & $6 \%$ & +10 & $\% 2$ & +3 & $\% 10$ & +10 & +10 & $\% 9$ & الإبداع والابتكار في التصميم \\
\hline$\% 100$ & 150 & $\% 100$ & 170 & $100 \%$ & 177 & $\% 100$ & 100 & $\% 100$ & 109 & المجموع (باستثناء الابتكار) \\
\hline
\end{tabular}




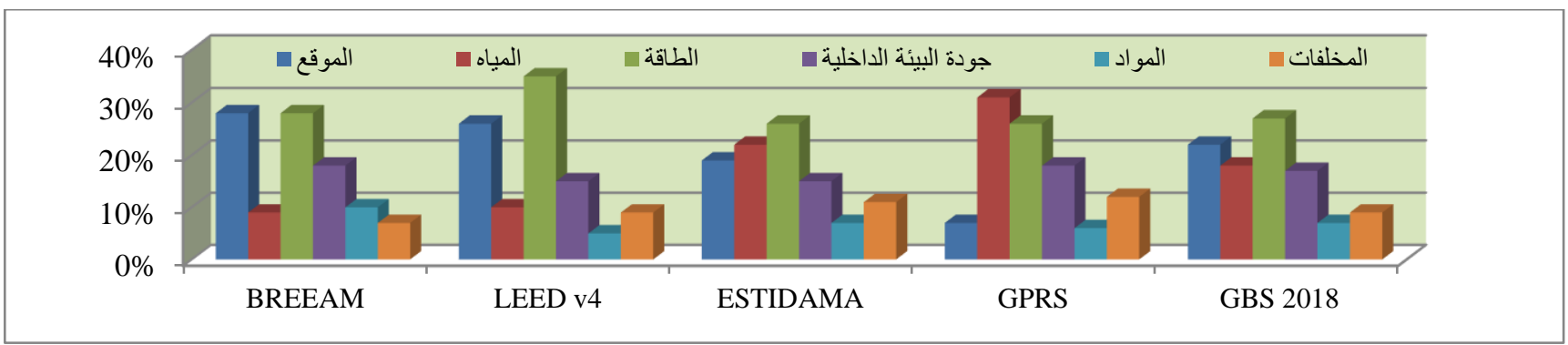

شكلرقم (5) نتائج المقارنة بين الأنظمة المختلفة والنظام المقترح من إعداد الباحثة

لانتاج واستخدام الطاقة المتجدة، وسجل النظام المقدة المقترح نسبة

27\% بقيمة 41 نقطة.

• أما بالنسبةإلى مبدأ جودة البيئة الداخلية يلاحظ التقارب النسبي بين النسب المئوية الخاصة بالبرامج المختلفة للأنظمة السابقة

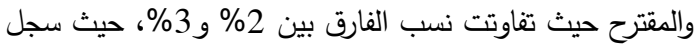
النظام المقترح نسبة 17\% بقيمة 25 نقطة. • بالنسبة إلى مبدأ كفاءة استخدام المواد نجد أن أعلى نسبة سجلها نظام BREEAM حيث سجل 10\% بقيمة 11 نقطة، بينما كان نظام الLEED هو أقلهم حيث سجل 5\% فقط بقيمة 5 نقاط، وسجل نظام GPRS سبة 6\% بقيمة 10 نقاط، وسجل النظام المقترح 2018 \% بقيمة 11 نقطة. • وأخيراً بالنسبةإلى مبدأ إدارة المخلفات الذي أخذ نسبة خاصة له له منفصلة عن مبدأ استهلاك المواد في الإصدارات الجديدة للعديد من الأنظمة مما يدل على كمية النفايات الكبيرة الناتجة من عملية

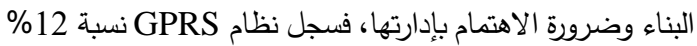
بقيمة 20 نقطة وهي أعلى نسبة بين الأنظمة وذلك لتركيز الاهتمام على المخلفات ومحاولة استخدامها مره ثانية، وسجل نظام ESTIDAMA النسبة التي تليه 11\% بقيمة 19 نقطة نظراً لاهتمام الإمارات بإدارة المخلفات، وكانت أقل نسبة 7 7 BREEAM 2018 إلى 9\% بقيمة 13 نقطة. وفيما يلي مقارنة تفصيلية بين البنود الفرعية داخل كل مبدأ من

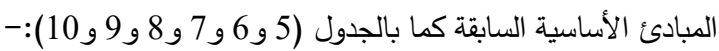

من خلال المقارنة بالجدول السابق رقم (4) والثكل السابق

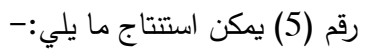

• بالنسبة إلى مبدأ احترام خصائص الموقع: يلاحظ من الثكل الثل السابق أن النظام المقترح2018 حقق نسبة 22\% بقيمة 33 نقطة، بينما حقق نظامBREEAM أعلى نسبة 28\% بقيمة 31 بقابه نقطة بفارق 2\% عن برنامج LEED، بعكس نظام الهرم الأخضر المصري أقل نسبة 7\% بقيمة 26 نقطة. • وبالنسبةإلى مبدأ كفاءة استهلاك المياه يلاحظ أن نظام GPRS قد سجل أعلى نسبة مئوية 31\%بقيمة 53 نقطة وذلك لظهور مشكلة نقص المياه في مصر واهتمام الدولة بحل هذه المشكلة، يليه برنامج Estidama الذي سجل 22\%بقيمة 39 نقطة مما يدل

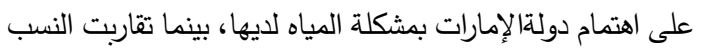

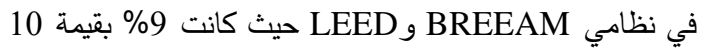
نقاط و10\% بقيمة 10 نقاط بالترتيب وهذا يدل على عدم أهمية

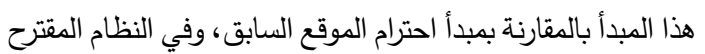
2018 حقق نسبة 18\% بقيمة 27 نقطة وهذه النسبة تدل على بلى بلى وجود المشكلة والت وجه العامل لدولة فى خفض استهلاك المياه.

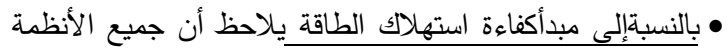
تقاربت في النسب المئوية الخاصة بها، في حين سجل نظام الLEED الأمريكي ارتقاعاً طفيفاً حيث حقق 35\% بقيمة 35

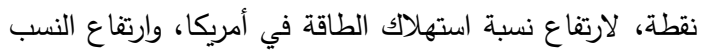

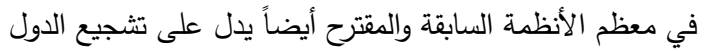

جدول (5): مقارنة بين النقاط الفرعية لمبد أاحترام خصائص الموقع:

\begin{tabular}{|c|c|c|c|c|c|c|c|c|c|c|c|}
\hline \multicolumn{2}{|c|}{$\begin{array}{l}\text { GBS } \\
2018 \\
\end{array}$} & \multicolumn{2}{|c|}{$\begin{array}{l}\text { GPRS } \\
2011 \\
\end{array}$} & \multicolumn{2}{|c|}{$\begin{array}{c}\text { PRS for } \\
\text { ESTIDAMAv1.0 } \\
\end{array}$} & \multicolumn{2}{|c|}{$\begin{array}{c}\text { LEED v4 } \\
\text { BD+C } 2014 \\
\end{array}$} & \multicolumn{2}{|c|}{$\begin{array}{l}\text { BREEAM } \\
\text { 2014UK } \\
\end{array}$} & \multicolumn{2}{|c|}{ استراتيجيات استدامة البناء الأخضر } \\
\hline $\begin{array}{c}2.8 \\
\%\end{array}$ & 4 & $1.2 \%$ & 2 & $2 \%$ & 3 & $6 \%$ & 6 & $3 \%$ & 3 & اختيار الموقع & \\
\hline $5 \%$ & 8 & $4 \%$ & 6 & $3 \%$ & 5 & $2 \%$ & 2 & $4 \%$ & 5 & علاقة المبنى بالبيئة المحبطة & \\
\hline $4 \%$ & 6 & $0.6 \%$ & 1 & $1 \%$ & 2 & - & - & $10 \%$ & 11 & جودة عملية الانشاء & \\
\hline $4 \%$ & 6 & $0.6 \%$ & 1 & $4 \%$ & 7 & $12 \%$ & 12 & $7 \%$ & 8 & استخدام وسائل النقل البديلة & \\
\hline $\begin{array}{c}2.8 \\
\%\end{array}$ & 4 & $0.6 \%$ & 1 & $6 \%$ & 10 & $1 \%$ & 1 & - & - & تصميم وتطوير الموقع & \\
\hline $\begin{array}{c}1.4 \\
\%\end{array}$ & 2 & - & - & $1 \%$ & 2 & $2 \%$ & 2 & $3 \%$ & 3 & إدارة مياه الأمطار & \\
\hline $\begin{array}{c}1.4 \\
\%\end{array}$ & 2 & - & - & $2.5 \%$ & 4 & $2 \%$ & 2 & - & - & الجزر الحرارية & \\
\hline
\end{tabular}




\begin{tabular}{|c|c|c|c|c|c|c|c|c|c|c|}
\hline $\begin{array}{l}0.6 \\
\% \\
\end{array}$ & 1 & - & - & $0.5 \%$ & 1 & $1 \%$ & 1 & $1 \%$ & 1 & تقليل التلوث الضوئى \\
\hline $\begin{array}{l}22 \\
\%\end{array}$ & 33 & $7 \%$ & 11 & $19 \%$ & 34 & $26 \%$ & 26 & $28 \%$ & 31 & مجموع النقاط \\
\hline
\end{tabular}

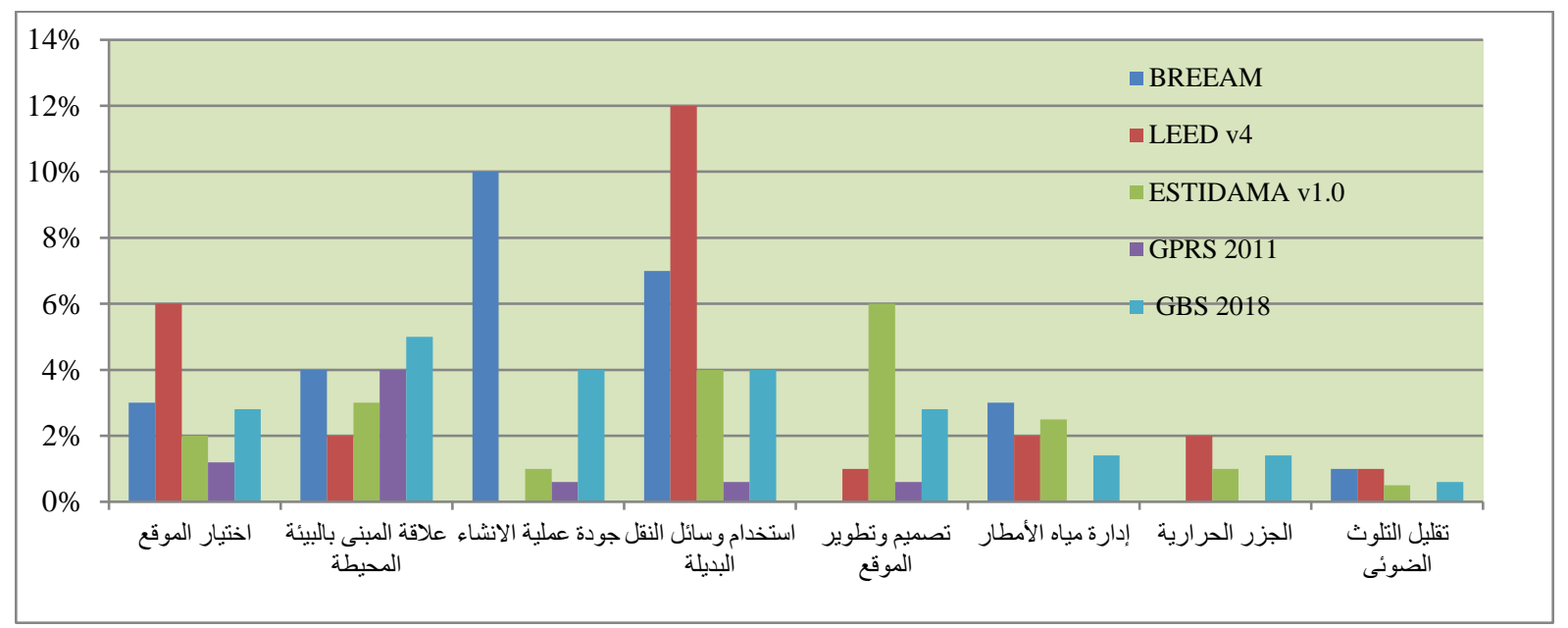

شكل رقم(6) توضيح لنتائج مقارنة البنودالفرعية لمبدأ احترام خصائص الموقع

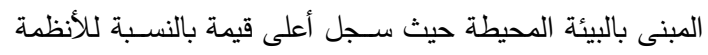

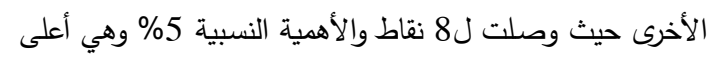

ومن خلال جدول المقارنات رقم (5) والثـكل السـابقرقم

نسبة وهذا يؤكد مدى أهمية البند بالنسبة للموقع في مصر .

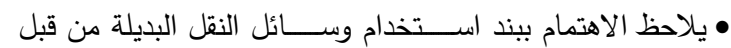
نظامLEED حيث ســـل أعلى نســـة 12\% بقديمة 12 نقطة

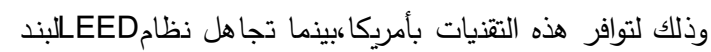
جودة عملية الإنشاء.

• بالنســبة لإدارة مياه الأمطار تجاهل نظام ESTIDAMA هذاء الإناء

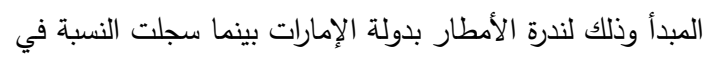

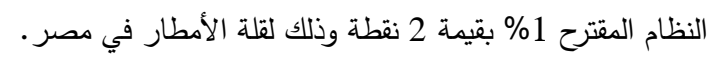

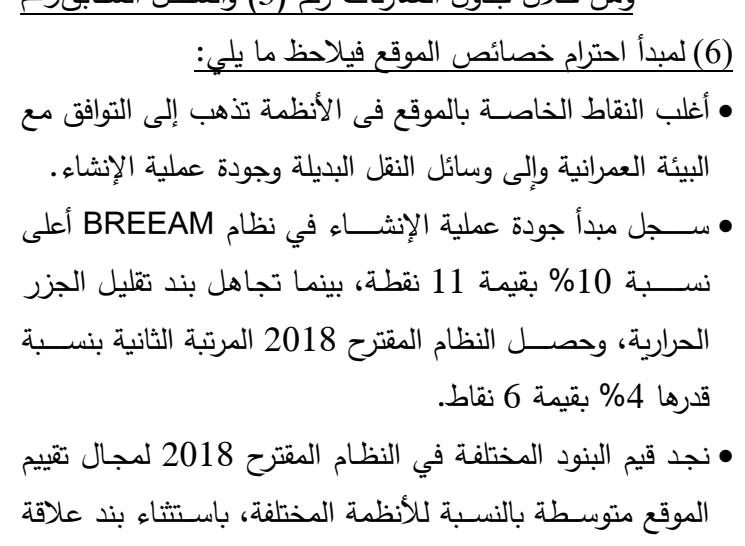

جدول (6): مقارنة بين النقاط الفرعية لمبدأ الكفاءة في استخدام المياه:

\begin{tabular}{|c|c|c|c|c|c|c|c|c|c|c|c|}
\hline \multicolumn{2}{|c|}{$\begin{array}{l}\text { GBS } \\
2018\end{array}$} & \multicolumn{2}{|c|}{$\begin{array}{l}\text { GPRS } \\
2011 \\
\end{array}$} & \multicolumn{2}{|c|}{$\begin{array}{c}\text { PRS for } \\
\text { ESTIDAMA v1.0 }\end{array}$} & \multicolumn{2}{|c|}{$\begin{array}{l}\text { LEED v4 } \\
\text { BD+C } 2014\end{array}$} & \multicolumn{2}{|c|}{$\begin{array}{l}\text { BREEAM } \\
\text { 2014UK }\end{array}$} & \multicolumn{2}{|c|}{ استراتيجيات استدامة البناء الأخضر } \\
\hline $11 \%$ & 16 & $19 \%$ & 32 & $19.8 \%$ & 35 & $2 \%$ & 2 & $3.6 \%$ & 4 & الترشيد في استهلاك المياه & \multirow{4}{*}{$\frac{y}{4}: \bar{y}$} \\
\hline $4 \%$ & 6 & $5 \%$ & 9 & $2.2 \%$ & 4 & $6 \%$ & 6 & $3.6 \%$ & 4 & مراقبة استهلاك المياه & \\
\hline $3 \%$ & 5 & $7 \%$ & 12 & - & - & $2 \%$ & 2 & $1.8 . \%$ & 2 & التدوير وإعادة استخدام المياه & \\
\hline$\% 18$ & 27 & $\% 31$ & 53 & $\% 22$ & 39 & $\% 10$ & 10 & $\% 9$ & 10 & مجموع النقاط & \\
\hline
\end{tabular}




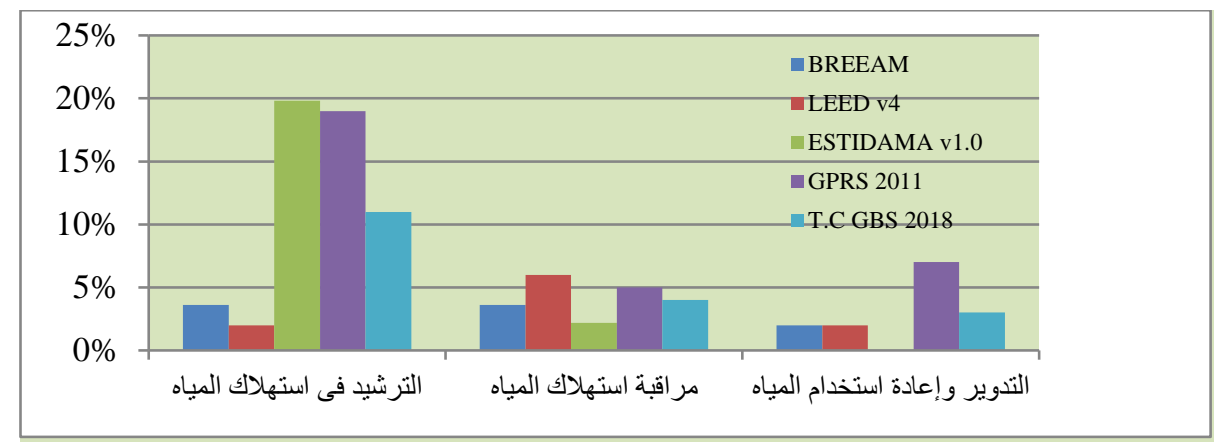

شكلرقم (7) توضيح لنتائج مقارنة البنود الفرعية لمبدأ كفاءة استهلاك المياه

المصـري بنسبة 5\% بقيمة 9 نقاط لمحاولة التحكم في مشـكلة المياه الراهنة وقياس الكمية المســـتهلكة لتقليلها والتغلب عليها

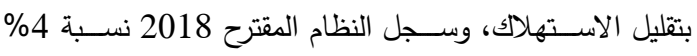
بقيمة 6 نقاط. • يلاحظأن نظام ESTIDAMA تجاهلتماماًاستخدام تقنيات تدوير

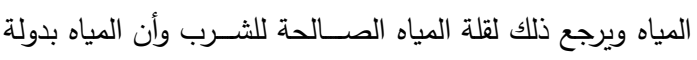
الإمارات مياه مالحة يتم تحليتها لاســتخدامها في الثــرب فتكون

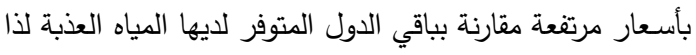

$$
\text { نجد الفاقد من مياه الثرب تكاد تكون معدومة. }
$$

بالنســبة إلى مبدأ كفاءة اســتهلاك المياه فيلاحظ من الجدول رقم (6)والثكل السابق رقم (7) مايلي: بالئ

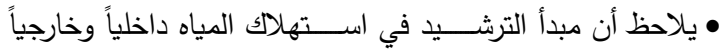
ســــلت أعلى نســـبة في كل الأنظمة الســــابقة ما عدا نظام LEED v4 ESTIDAMA

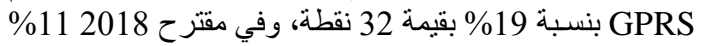
بقيمة 16 نقطة. • يلاحظ اهتمام نظام LEED v4 بأنظمة قياس اســتهلاك المياه بواسـطة العدادات التى تسـاعدعلى تقليل اسـتهلاك المياه حيث

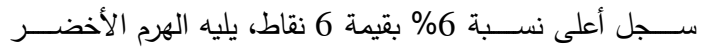

جدول (7): مقارنة بين النقاط الفرعية لمبدأ كفاءة استهلاك الطاقـة:

\begin{tabular}{|c|c|c|c|c|c|c|c|c|c|c|c|}
\hline \multicolumn{2}{|c|}{$\begin{array}{l}\text { GBS } \\
2018 \\
\end{array}$} & \multicolumn{2}{|c|}{$\begin{array}{c}\text { GPRS } \\
2011\end{array}$} & \multicolumn{2}{|c|}{$\begin{array}{c}\text { PRS for } \\
\text { ESTIDAMAV1.0 }\end{array}$} & \multicolumn{2}{|c|}{$\begin{array}{l}\text { LEED v4 } \\
\text { BD+C2014 }\end{array}$} & \multicolumn{2}{|c|}{$\begin{array}{l}\text { BREEAM } \\
\text { 2014UK }\end{array}$} & \multicolumn{2}{|c|}{ استراتيجيات استدامة البناء الأخضر } \\
\hline $17.5 \%$ & 25 & $14 \%$ & 24 & $15 \%$ & 27 & $19 \%$ & 19 & $18 \%$ & 19 & ترشيد استهلاك الطاقة & \multirow{5}{*}{$\begin{array}{l}y \\
\frac{y}{a} \\
\frac{0}{3} \\
\frac{7}{3} \\
\frac{7}{2}\end{array}$} \\
\hline $5.28 \%$ & 8 & $7 \%$ & 12 & $5 \%$ & 9 & $9 \%$ & 9 & - & - & توظيف مصادر الطاقة المتجددة & \\
\hline $2.64 \%$ & 4 & $\% 4$ & 7 & $4 \%$ & 6 & $7 \%$ & 7 & $2 \%$ & 2 & رصد مراقبة آداء المبنى & \\
\hline$\% 2.64$ & 4 & $1 \%$ & 2 & $2 \%$ & 4 & - & - & $8 \%$ & 9 & القضاء الملوثات الهوائية & \\
\hline $27 \%$ & 41 & $\% 26$ & 45 & $\% 26$ & 46 & $\% 35$ & 35 & $\% 28$ & 30 & مجموع النقاط & \\
\hline
\end{tabular}

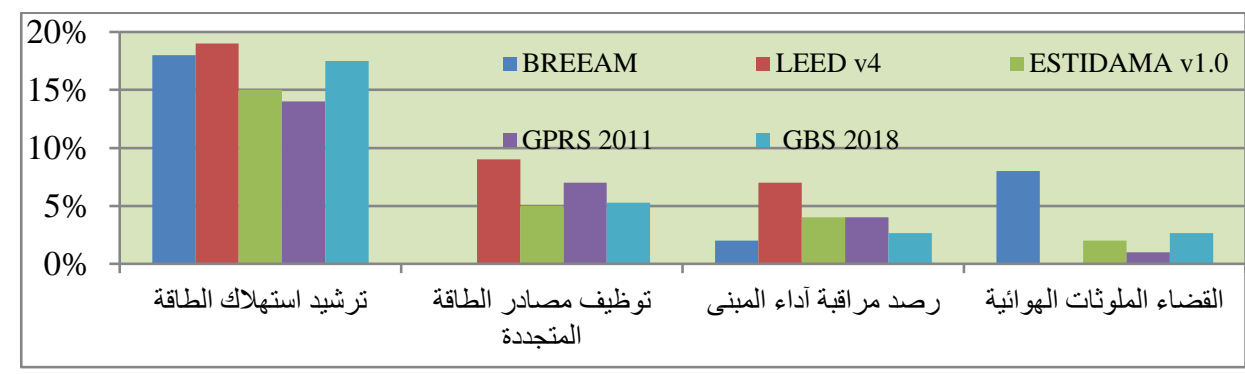

شكل رقم (8) توضيح لنتائج مقارنةا لبنودالفرعية لمبدأ كفاءةاستهلاك الطاقة.

كان النظام المصـري GPRS بنسبة 14\% بقيمة 24

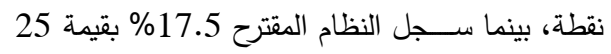
نقطة وذلك لزيادة اهتمام الدولة بترشيد استهلاك الطاقة

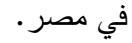
• اهتمام نظام GPRS بمبدأ توظيف مصــــادر الطاقة

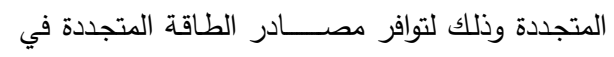
مصر كالطاقة الثمسية والرياح، فسجل 7\% بقديمة 12 نقطة، ويليه مقترح 2018 حيث سـجل 5.28\% بقيمة
بالنســـةإلى مبدأ كفاءة اســتهلاك الطاقة فيلاحظ من الجدول رقم

$$
\text { (7)والثكل السابق رقم (8) مايلي: بالئ }
$$

• أن أغلب النقاط الخاصــة بالطاقة فى الأنظمة السـابقة

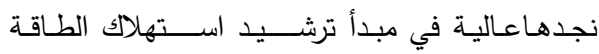

وتحسينآداءها، حيث تجاوز هذا المبدأ أكثر من 50\%

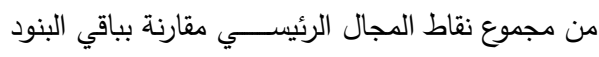

الفرعية الخاصـة بالطاقة، فنجد أعلى نسبة سجلها نظام

LEED فحصــل على 19\% بقيمة 19 نقطة، وأقلهم 


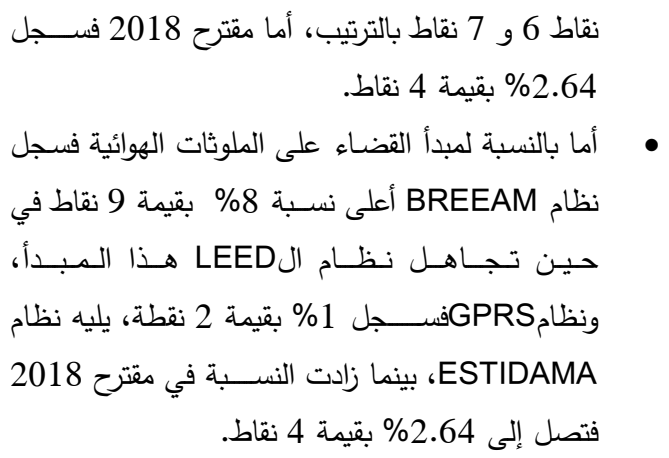

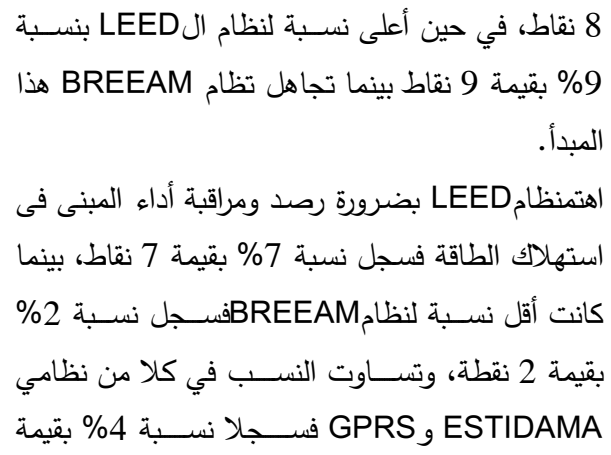

جدول (8): مقارنة بين النقاط الفرعية لمبدأ تحقيق جودة البيئة الداخلية:

\begin{tabular}{|c|c|c|c|c|c|c|c|c|c|c|c|}
\hline \multicolumn{2}{|c|}{$\begin{array}{l}\text { GBS } \\
2018 \\
\end{array}$} & \multicolumn{2}{|c|}{$\begin{array}{c}\text { GPRS } \\
2011 \\
\end{array}$} & \multicolumn{2}{|c|}{$\begin{array}{c}\text { PRS for } \\
\text { ESTIDAMA v1.0 } \\
\end{array}$} & \multicolumn{2}{|c|}{$\begin{array}{r}\text { LEED v4 } \\
\text { BD+C } 2014 \\
\end{array}$} & \multicolumn{2}{|c|}{$\begin{array}{l}\text { BREEAM } \\
\text { 2014UK } \\
\end{array}$} & \multicolumn{2}{|c|}{ استراتيجيات استدامة البناء الأخضر } \\
\hline$\% 2.7$ & 4 & $3 \%$ & 5 & $3.5 \%$ & 6 & $5 \%$ & 5 & $3 \%$ & 3 & تزويد المباني بالتهوية الطبيعية & \\
\hline $4.1 \%$ & 6 & $5 \%$ & 9 & $3.5 \%$ & 6 & $5 \%$ & 5 & $2 \%$ & 2 & منع ومكافحة الملوثات & $y$ \\
\hline $2 \%$ & 3 & $1.2 \%$ & 2 & $2.5 \%$ & 4 & $4 \%$ & 4 & $5 \%$ & 6 & تحقيق الراحة البصرية & \\
\hline $3 \%$ & 4.5 & $5 \%$ & 9 & $3 \%$ & 5 & $2 \%$ & 2 & $3 \%$ & 3 & تحقيق الراحة الحرارية & D \\
\hline$\% 0.68$ & 1 & $0.8 \%$ & 1 & $0.6 \%$ & 1 & - & - & $2 \%$ & 2 & تحقيق الراحة الصوتية & $\overline{7}$ \\
\hline$\% 0.68$ & 1 & - & - & $0.6 \%$ & 1 & - & - & - & - & تحقيق الأمن والأمـان & $\overline{7}$ \\
\hline$\% 8.2$ & 12 & $3 \%$ & 5 & $1.3 \%$ & 3 & - & - & $3 \%$ & 3 & جودة التصميم الداخلي & $\mathcal{7}$ \\
\hline $17 \%$ & 25 & $\% 18$ & 31 & $\% 15$ & 26 & $\% 15$ & 15 & $\% 18$ & 19 & مجموع النقاط & \\
\hline
\end{tabular}

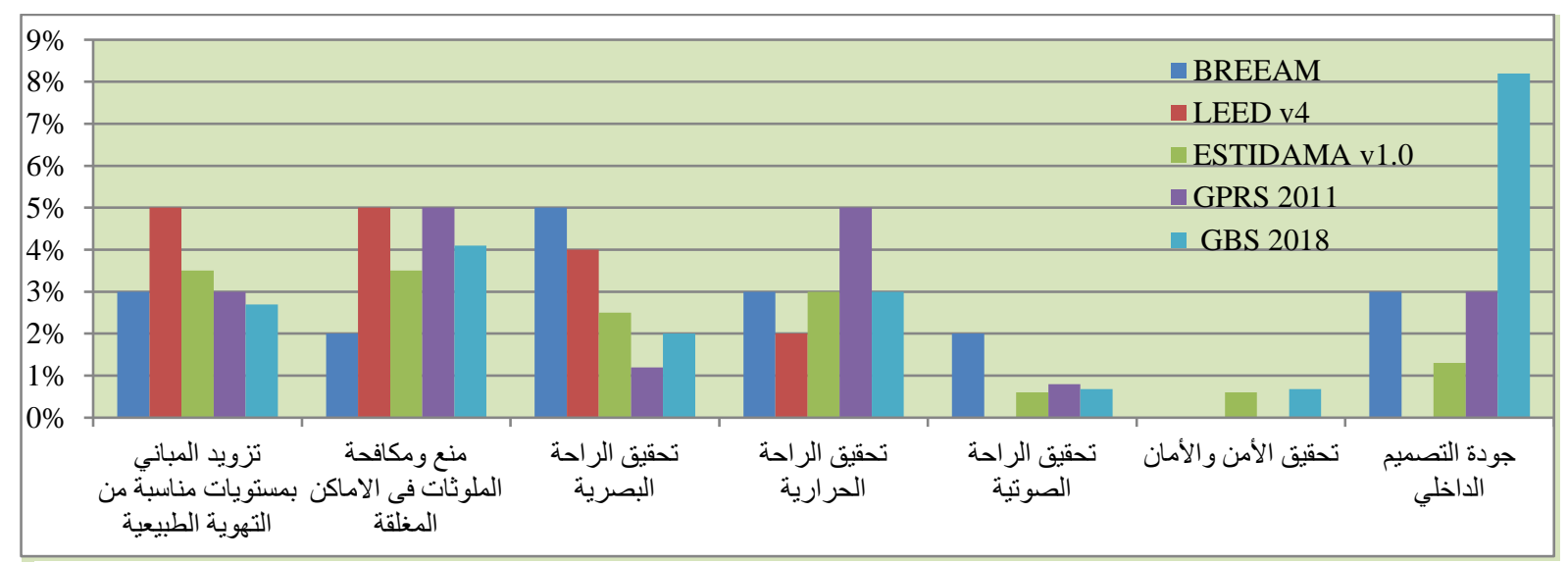

شكل رقم (9) توضيح لنتائج مقارنة البنود الفرعية لمبدأ تحسين جودة البيئة الداخلية

بلغت النسبة 1.1\% بقيمة 6 نقاط نظراً لزيادة نسبة التلوث في الهواء وضرورة الاهتمام بمكافحة تلك الملوثات. • تجاهل نظام LEED ثلاث بنود وهم تحقيق الراحة الصـــــية و و تحقيق الأمن والأمان و جودة التصميم الاخلي.

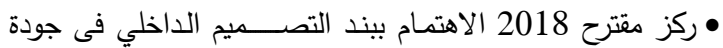
البيئة الداخلية حيث ســــل أعلى نســـبة بين الأنظمة المختلفة فسجت 8.2\% بقيمة 12 نقطة.
بالنسـبة إلى مبدأ تحسـين جودة البيئة الداخلية فيلاحظ من الجدول

$$
\text { رقم (8) والثكلال سابق رقم (9) مايلي: }
$$

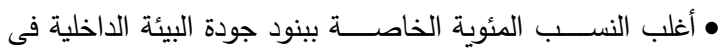
الأنظمة السـابقة تزداد في بند منع ومكافحة لملوثات فى الأماكن

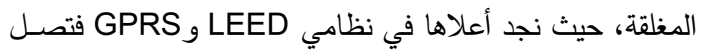
إلى 5\% بقيمة 5 و نقاط بالترتيب، بينما نجد أقل نسبة في نظام

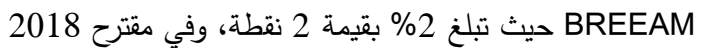


ESTIDAMA

بقيمة نقطة واحدة.
• بالنسـبة لمبدأ تحقيق الأمن والأمان نجد أنه لم يحقق أهمية كبيرة في معظم الأنظمة السـابقة، حيث تجاهل نظام

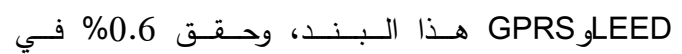

جدول (9): مقارنة بين النقاط الفرعية لمبدأ كفاءة مواد البناء:

\begin{tabular}{|c|c|c|c|c|c|c|c|c|c|c|c|}
\hline \multicolumn{2}{|c|}{$\begin{array}{l}\text { GBS } \\
2018 \\
\end{array}$} & \multicolumn{2}{|c|}{$\begin{array}{c}\text { GPRS } \\
2011 \\
\end{array}$} & \multicolumn{2}{|c|}{$\begin{array}{c}\text { PRS for } \\
\text { ESTIDAMAv1.0 } \\
\end{array}$} & \multicolumn{2}{|c|}{$\begin{array}{l}\text { LEED v4 } \\
\text { BD+C } 2014 \\
\end{array}$} & \multicolumn{2}{|c|}{$\begin{array}{l}\text { BREEAM } \\
\text { 2014UK } \\
\end{array}$} & \multicolumn{2}{|c|}{ استراتيجيات استدامة البناء الأخضر } \\
\hline $5.76 \%$ & 9 & $5.4 \%$ & 9 & $3.5 \%$ & 6 & $4 \%$ & 4 & $9 \%$ & 10 & اختيارمواصفات مواد البناء & \multirow{4}{*}{ 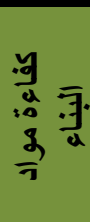 } \\
\hline $0.96 \%$ & 1.5 & $0.6 \%$ & 1 & $2.5 \%$ & 4 & $1 \%$ & 1 & - & - & الإقتصاد والتكلفة & \\
\hline $0.64 \%$ & 1 & - & - & $1 \%$ & 3 & - & - & $1 \%$ & 1 & تجنب استخدام المواد الملوثة & \\
\hline $7 \%$ & 11 & $\% 6$ & 10 & $\% 7$ & 13 & $\% 5$ & 5 & $\% 10$ & 11 & مجموع النقاط & \\
\hline
\end{tabular}

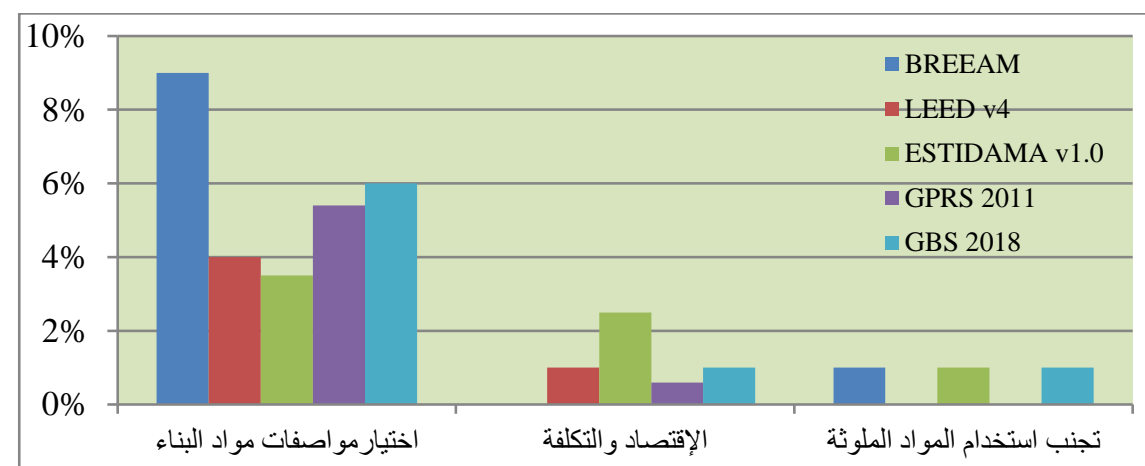

شكل رقم (10): توضيح لنتائج مقارنة البنود الفرعية لمبدأ كفاءة استخدام مواد البناء

بنبة قليلة جداً في مقترح 2018 حيث ســـجل نســـة 0.7 بقيمة نقطة واحدة. • أما بالنسبة للإقتصاد والتكلفة فتساوت النسب في مقةد في مقرح

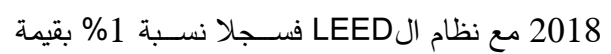
1.5 نقطة ونقطة واحدة على التوالي، في حين كانت أعلى نسـبة لنظام ESTIDAMA بقيمة 2.5\% بقيطة واحة فئل

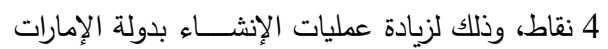
مع اســتخدام مواد تثـــيب وخامات إنثــائية عديدة فيثــترط أن تكوم مواد بيئية محققة لمعايير مبدأ كفاءة مواد البناء ودون هدر اقتصادي.
بالنســةإلى مبدأكفاءة اسـتخدام مواد البناء فيلاحظ من الجدول رقم (9) والثكل السابق رقم (10) مايلي: لئل

تتجه أعلى نســب إلى بمبدأ كفاءة اسـتخدام مواد البناء فى الأنظمة إلى بند اسـتخدام مواد بناء خضــراء وذات مواصـفات جيدة بيئياً، حيث ســـل أعلى نســة نظـام

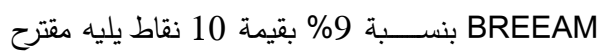
2018 بنسبة 6\% بقيمة 9 نقاط.

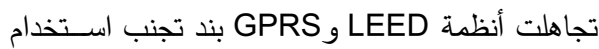
المواد الملوثـة، في حين كـان النظـامين BREEAM \% أعطوا نسـب ولكن ضـئيلة بقيمة 10STIDAMA, بقيمة نقطة واحدة و3 نقاط على التوالي، وقلت النسـبة 
جدول (10): مقارنة بين النقاط الفرعية لمبدأ إدارة المخلفـات:

\begin{tabular}{|c|c|c|c|c|c|c|c|c|c|c|c|}
\hline \multicolumn{2}{|c|}{$\begin{array}{l}\text { GBS } \\
2018 \\
\end{array}$} & \multicolumn{2}{|c|}{$\begin{array}{c}\text { GPRS } \\
2011 \\
\end{array}$} & \multicolumn{2}{|c|}{$\begin{array}{c}\text { PRS for } \\
\text { ESTIDAMAv1.0 } \\
\end{array}$} & \multicolumn{2}{|c|}{$\begin{array}{l}\text { LEED v4 } \\
\text { BD+C2014 } \\
\end{array}$} & \multicolumn{2}{|c|}{$\begin{array}{c}\text { BREEAM } \\
\text { 2014UK } \\
\end{array}$} & \multicolumn{2}{|c|}{ استراتيجيات استدامة البناء الأخضر } \\
\hline $2 \%$ & 3 & $4 \%$ & 7 & $2.5 \%$ & 4 & $4 \%$ & 4 & $2.5 \%$ & 3 & الترشيد في الاستهلاك & 亏 \\
\hline $3.5 \%$ & 5 & $6.5 \%$ & 11 & $4 \%$ & 7 & $5 \%$ & 5 & $2.5 \%$ & 3 & إعادة الاستخدام & \\
\hline $3.5 \%$ & 5 & $1.5 \%$ & 2 & $3.5 \%$ & 6 & - & - & $2 \%$ & 2 & إعادة التدوير & $\frac{\overline{3}}{7}$ \\
\hline- & - & - & - & $1 \%$ & 2 & - & - & - & - & التخلص النهائيواستعادة الطاقة & \\
\hline $9 \%$ & 13 & $\% 12$ & 20 & $\% 11$ & 19 & $\% 9$ & 9 & $\% 7$ & 8 & مجموع النقاط & \\
\hline
\end{tabular}

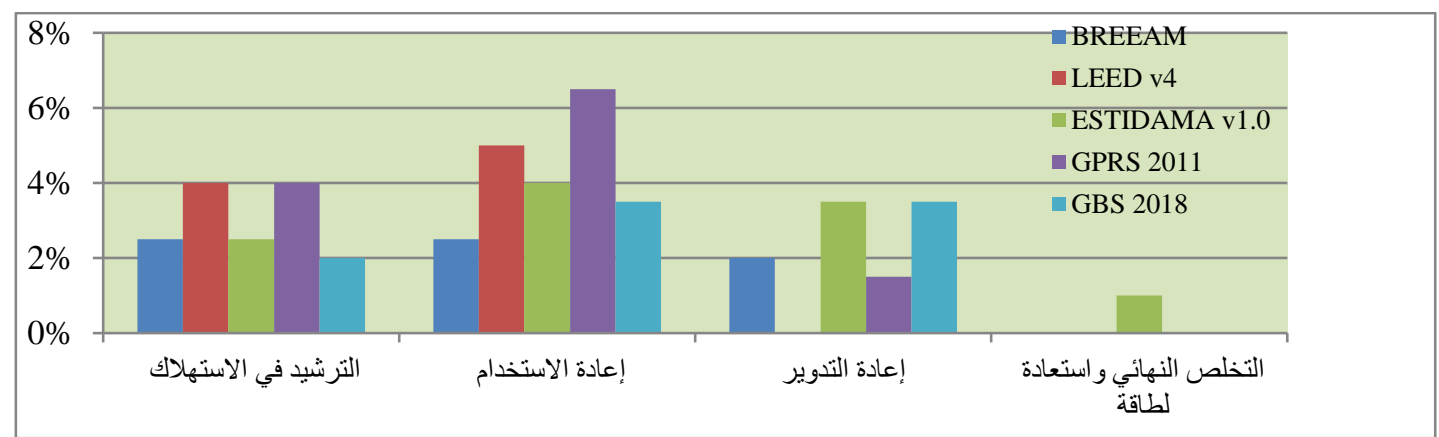

شكل رقم (11): توضيح لنتائج مقارنة البنود الفرعية لمبدأ إدارة المخلفات

* أما بالنسبة لمبدأ الإبداع يبلغ قيمة التقييم 10 نقاط إضافية على إلى مجموع تقييم المجالات الرئيسية ولا يتم احتساب نسبة مئوية له له لهابله في جميع الأنظمة التي تم اختيارها والمقترح

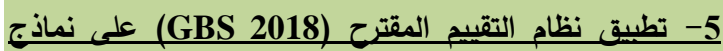
للمباني التقليدية والمعاصرة في مصر : تم اختيار عدد أربع نماذج لمباني محلية في مصر مصرف نموذجان ممثلان للعمارة التقليدية ونموذجان آخران ممثلان للعمارة المعاصرة ويتم عمل التحليل المقارن فيما بينهم طبقاً لمعايير تقييم الاستدامة وبما يحقق أهداف الدراسة، ومن ثم تطبيق التقييم المقترح عليهم لاستخلاص أعلى نسب لمجالات التقييم محققة في المباني

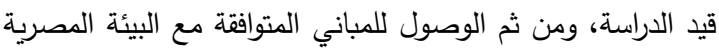
ومحققة لمعايير الاستدامة ومبادئ العمارة الخضراء،وهي كما يلي: أ- نماذج المباني التقليدية: بيت السحيمي بالقاهرة القديمةبيت الكريتيلية بالقاهرة القديمة.

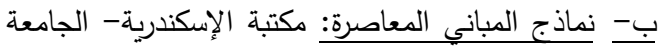
الأمريكية بالتجمع الخامس القاهرة الجديدة.

ومن خلال الجدول رقم (11) يتم عمل تحليل مقارن للنماذج البنائية التي تم اختيارها للدراسة من خلال مجالات الاستدامة البيئية:
بالنسبة إلى مبدا كفاءة إدارة المخلفات في لاحظمن الجدولرقم (10) والثكل السابق رقم (11) مايلي:

•تجه أغلب النسب المئوية للأنظمة المختلفة لبند إعادة

الاستخدام حيث تبلغ أعلى نسبة في نظام GPRS المصري بنسبة 6.5\% بقيمة 11 نقطة، يليه نظام فتبلغ النسبة 5ED ESTIDAMA

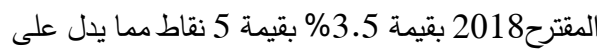
أهمية إعادة استخدام المواد مرة أخرى الناتجة من أعمال البناء أو مخلفات المباني. وبالنسبة لمبدأ إعادة التدوير الذي أصبح محل اهتمام

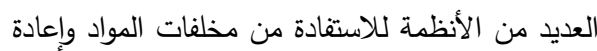
تصنيعها مرة أخرى، فبلغت أعلى نسبة في مقترح

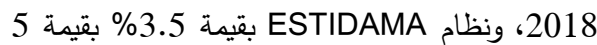
نقاط و6 نقاط على التوالي، ثم نظام BREEAM بقيمة

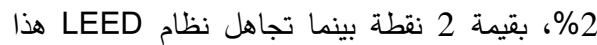
البند. وأخيراً فيما يخص بند التخلص النهائي واستعادة الطاقة فنجد أن نظام ESTIDAMA هو الوحيد الذي حقق نسبة بقيمة 1\% بقيمة 2 نقطة. 
Journal of Advanced Engineering Technology (JAET), Vol. 39, No. 1. January 2020

جدول (11) مقارنة بين نتائج تحليل مجالات تقييم الاستدامة لنماذج المباني بالدراسة التطبيقية:

\begin{tabular}{|c|c|c|c|c|}
\hline مبنى المكتبة بالجامعة الأمريكية & مكتبة الإسكندرية & بيت الكريتيلية & & المجالا \\
\hline 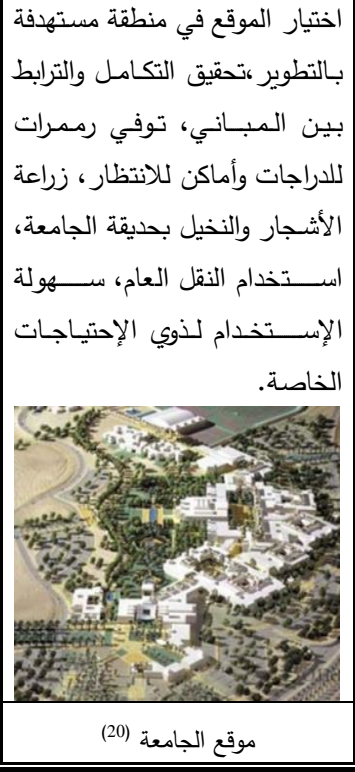 & 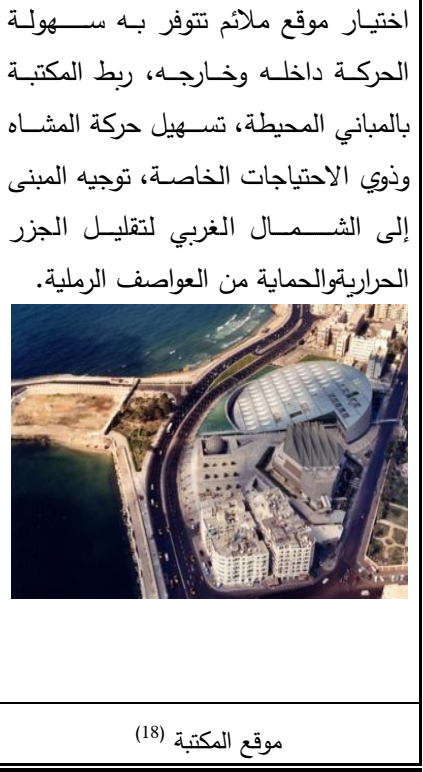 & 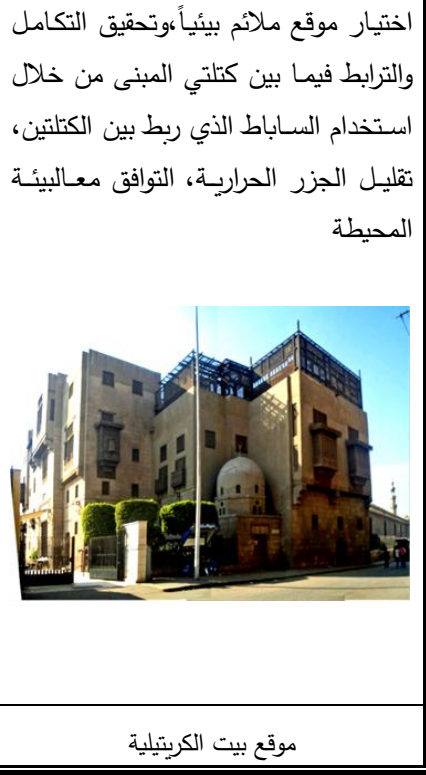 & 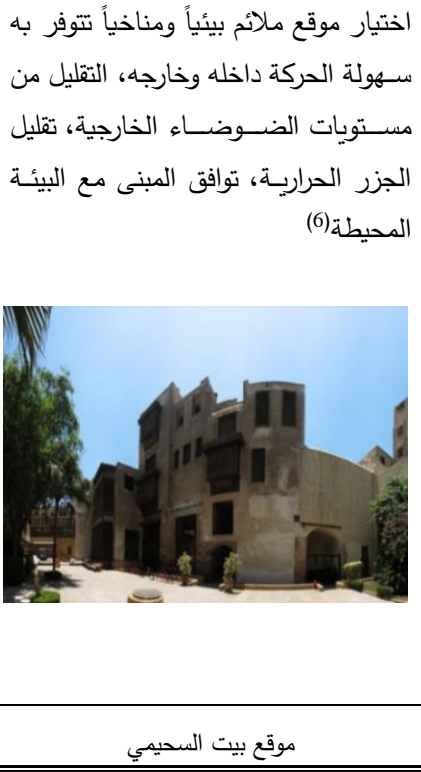 & '人 \\
\hline 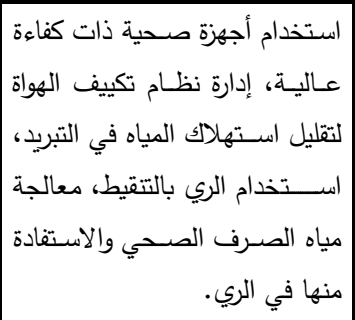 & 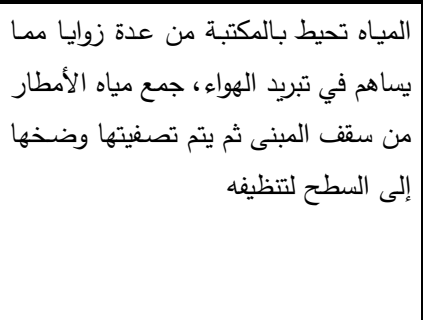 & 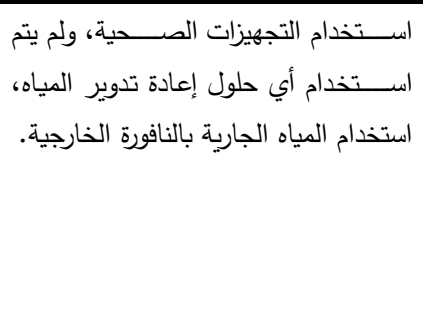 & 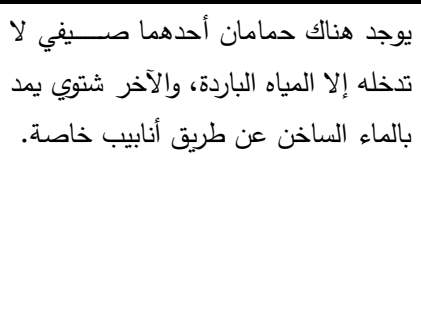 & $\overline{7}$ \\
\hline
\end{tabular}


تابع جدول (11) مقارنة بين نتائج تحليل مجالات تقييم الاستدامة لنماذج المباني بالدراسة التطبيقية:

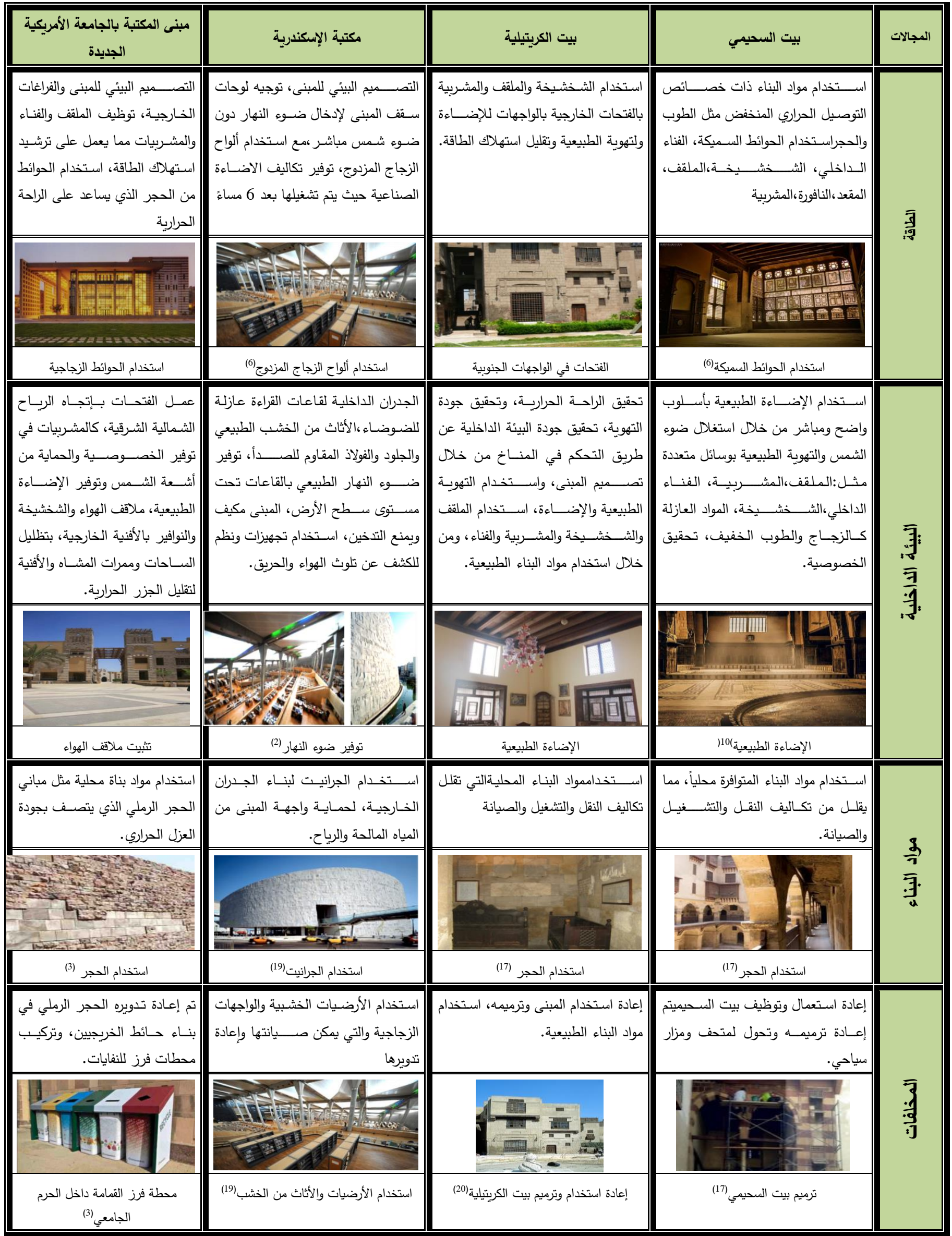




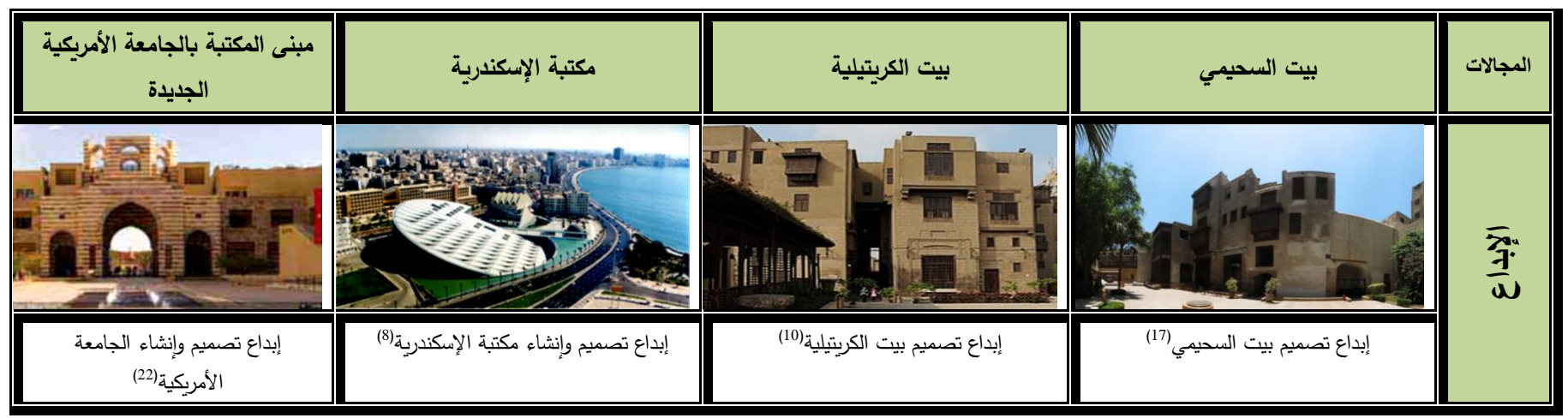

من إعداد الباحثة
التقييم للمباني الأربعة، كما يوضح الثكل رقم (12)الوزن
وبعد التحليل السابق يتم تقييم تلك المباني التي تم اختيارها
النسبيلمجالات التقييم وذلك بناءاً على الدراسات السابقة وآراء
قيد الدراسة للتوصل إلى العمارة المحققة لأعلى نسب لاستراتيجيات
الباحثين والخبراء.

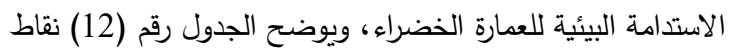

جدول (12) نقاط التقييم والأوزان النسبية (بيت السحيمي- بيت الكريتيلية)، (مكتبة الإسكندرية-مكتبة الجامعة الأمريكية الجديدة):

\begin{tabular}{|c|c|c|c|c|c|c|c|c|c|c|}
\hline \multicolumn{2}{|c|}{ مكتبة الجامعة } & \multicolumn{2}{|c|}{ مكتبة الإسكندرية } & \multicolumn{2}{|c|}{ بيت الكريتيلية } & \multicolumn{2}{|c|}{ بيت السحيمي } & \multicolumn{3}{|c|}{2018 GBS نظام التقييم المقترح } \\
\hline النسبي & النقاط & الوزن النسبي & النقاط & الوزن النسبي & النقاط & الوزن النسبي & النقاط & الوزن النسبي & النقاط & المجالات \\
\hline$\% 21$ & 31 & $\% 19$ & 28 & $\% 15$ & 23 & $\% 19$ & 28 & $22 \%$ & 33 & الموقع \\
\hline$\% 15.5$ & 23 & $\% 12$ & 18 & $\% 5$ & 8 & $\% 9$ & 13.5 & $18 \%$ & 27 & المياه \\
\hline$\% 24.5$ & 37 & $\% 19$ & 29 & $\% 19$ & 29 & $\% 19$ & 29 & $27 \%$ & 41 & الطاقة \\
\hline$\% 17$ & 25 & $\% 15$ & 22 & $\% 13.5$ & 20 & $\% 13.5$ & 20 & $17 \%$ & 25 & البيئة الداخلية \\
\hline$\% 6$ & 9.5 & $\% 5$ & 8 & $\% 5$ & 8 & $\% 5$ & 8 & $7 \%$ & 11 & مواد البناء \\
\hline$\% 7$ & 10.5 & $\% 3$ & 4 & $\% 3.5$ & 5 & $\% 4.5$ & 6.5 & $9 \%$ & 13 & المخلفات \\
\hline- & $10+$ & - & $9+$ & - & $7+$ & - & $6+$ & - & $10+$ & الإبداع \\
\hline$\% 90$ & 136 & $\% 73$ & 109 & $\% 62$ & 93 & $\% 70$ & 105 & $100 \%$ & 150 & المجموع \\
\hline \multicolumn{2}{|c|}{ البلاتيني(الأخضرى) } & \multicolumn{2}{|c|}{ المستوى الأهبي } & \multicolumn{2}{|c|}{ المستوى الفضي } & \multicolumn{2}{|c|}{ المستوى الأهبي } & \multicolumn{3}{|c|}{ مستويات التقييم } \\
\hline
\end{tabular}

من إعداد الباحثة

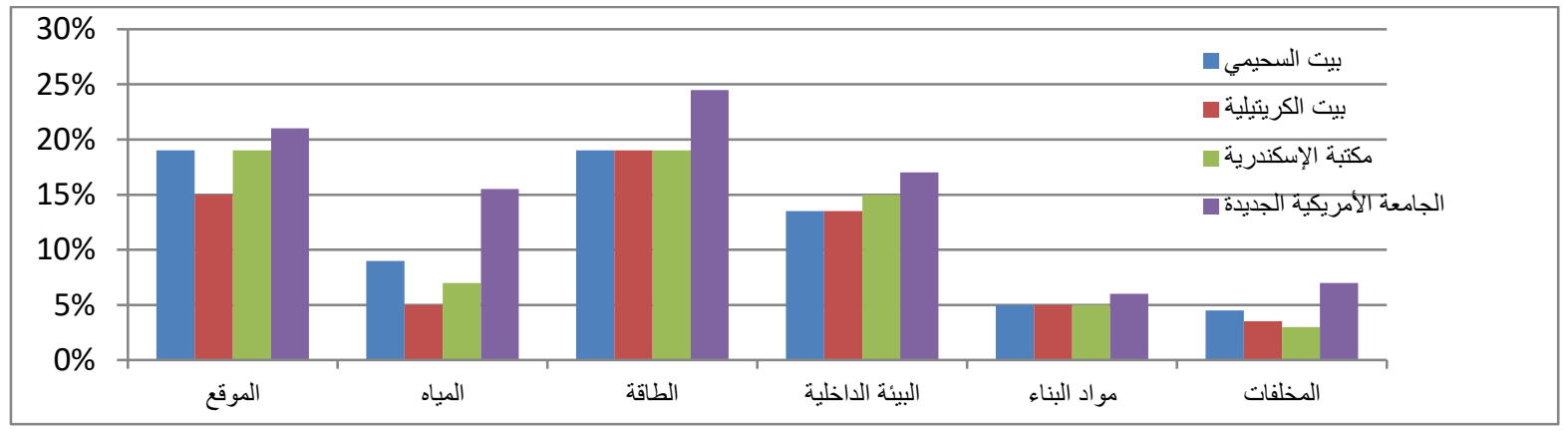

من إعداد الباحثة

شكلرقم (12) نتائج التقييم البيئي لنماذج من المباني التقليدية والمعاصرة في مصر

28 نقطة بنســبة 19\%، بينما قل بيت الكريتيلية حيث حصــلـل على 23 نقطة بقيمة 15\%، وكان أعلى تقييم

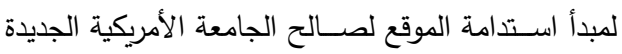
حيث حصلت على 31 نقطة بنسبة 21\%.
ومن خلال تطبيق نظام التقييم المقترح GBS-2018 على نماذج

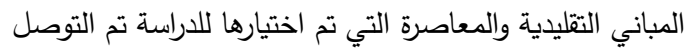

إلى :

أ- الموقع المســـــام: توافق مبنى بيت الســــيمي ومكتبة

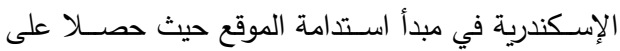


وبالتالى ينعكس على لتحسـين مسـتوى الأفراداجتماعياً واقتصـادياً، وقد خلص البحث إلى مجموعة من النتائج والتوصيات والتي تتمثل في النقاط التالية:-1-6

1. تهدف العمارة الخضراء المستدامة إلى تقليل الآثر السلبي على البيئة الطبيعية والمشيدة والحد من استهلاك الموارد غير القابلة

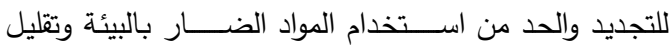
استهلاك الطاقة.

2. تختلف أسـس اسـتراتيجيات الاســتامة البيئية لكنها مترابطة ومتداخلة ولايمكن الفصـــلـل فيما بينها، وتتمثل في: الموقع المســــدام- الحفاظ على المياه- الحفاظ على الطاقة- كفاءة البيئة الداخلية- إدارة المواد والموارد - إدارة النفايات.

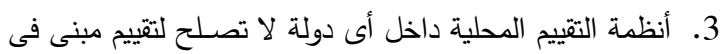

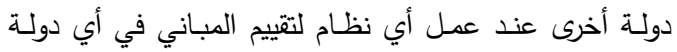

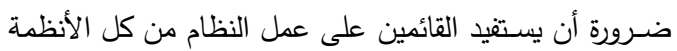
الســابقة والمطبقة بالفعل حتى يســتطيعوا التأكيد على المزايا

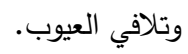

4. تتغير النقاط الفرعية داخل كل مبدأ من مبادئ واســتراتيجيات

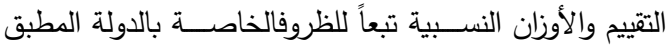
بها، ومن خلال الدراســــة التحليلية المقارنة للأنظمة العالمية بالية ونظام الهرم المصـري توصـلت الورقة البحثية إلى نظام تقييم مقترح للمباني في مصـر والتي تم وضــع مجالات التقييم طبقاً لاستراتيجيات الاستدامة البيئية والتي تتمثل في النقاط التالية:أ- الموقع المستدام: ويشمل مجموعة من الاستراتيجيات التي لتئي

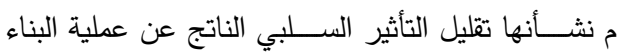
وعلاقة المبنى بالبيئة المحيطة، تشـجيع اسـتخدام وسـائل النقل البديلة،حيث وصـلت نقاط تقييم البند إلى 33 نقطة لنه

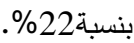

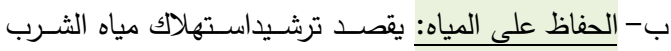
والاســتفادة قدر الإمكان من موارد أخري للمياه مثل مياه

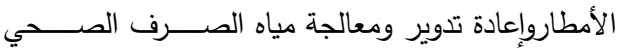
لاســـتعمالها بدل مياه الثـــرب في ري النباتات، حيث لـيث وصلت نقاط تقييم البند إلى 27 نقطة بنسبة 18\%. ج- الحفاظ على الطاقة: يهدف ال نتصميم بيئي يتم فيه تقليل

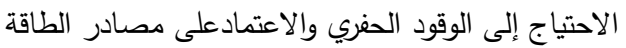

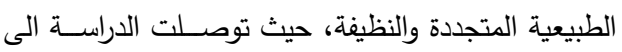
أن نقاط تقييم البند إلى 41 نقطة بنسبة 27\%

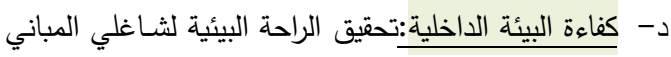
المتمثلـة في التهويـة ودرجـة الحرارة والرطوبـة والإنـارة

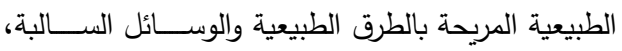

ووصلت نقاط تقييم البند إلى 25 نقطة بنسبة 17\% هـ - إدارة المواد والموارد:مراعاة تقليل اســـتخدام المواردالجديدة في المباني واختيار الخامات المناســــبة والغير ضــــــــارة
ب-الحفاظ على المياه: بلغ أعلى تقييم لمكتبة حرم الجامعة

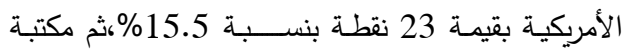

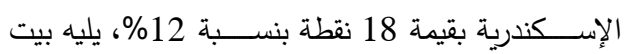

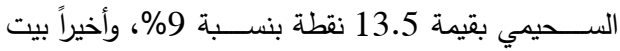

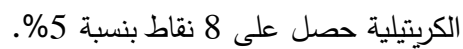

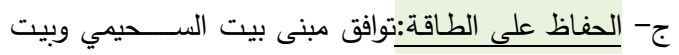
الكريتيلية ومكتبة الإسـكندرية في مبدأ الحفاظ على الطاقة

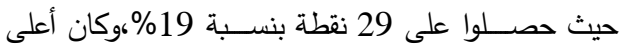
تقييم لصــالح الجامعة الأمريكية الجديدة حيث حصلئ حصـلت على37 نقطة بنسبة 24.5\%.

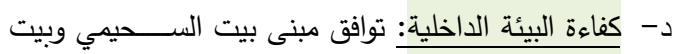

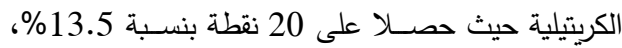
ثم يليهما مكتبة الإسكندرية بقيمة 22 نقطة بنسبة 15\%، وكان أعلى تقييم للجامعة الأمريكية الجديدة حيث حصلت لتصنه على 25 نقطة بنسبة 17\% هـ - إدارة المواد والموارد توافق مبنى بيت الســـــيمي وبيت

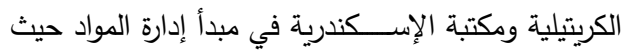

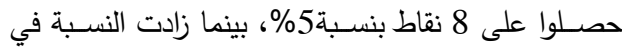
الجامعة الأمريكية الجديدة حيث حصلت لعاط على 9.5 نقطة بنسبة 6\%. و- إدارة النفـايـات: بلغت أقل نســـبـة تقييم لمبنى مكتبـة الإسكندرية حيث حصلت على 4 نقاط بنسبة 3\%، يليه بيت الكريلية حيث ارتفع عنها بنسبة ضئيلة فحصل على حلى بلى 5 نقاط بنسبة 3.5\%، ثم زادت القيمة في بيت السحيمي

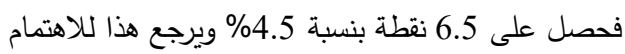

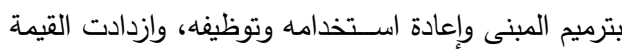
بالحرم الجامعي حيث حصـلت الجامعة على 10.5 نقاط واط واند بنسبة 7\%.

توصلت الدراسـة التطبيقية إلى أن المباني التقليدية حققت نسب عالية في مجالات التقييم، حيث حصل مبنى بيت السحيمي على إجمالي تقييم 105 نقطة بنسبة 70\% وبالتالي يكون حصـل ملــ على المســوى الذهبي، وحصـل بيت الكريتيلية على مجموع نقاط

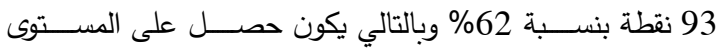

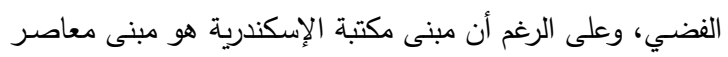

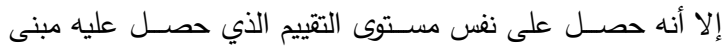

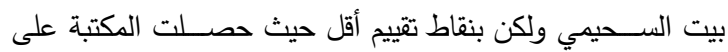
109 نقطة بنســبة 73\%، وكان أعلى مجموع تقييم لمكتبة حرم

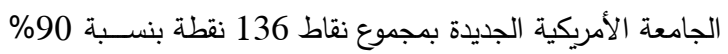

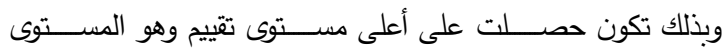
البلاتيني (الأخضر). 6- نتائج وتوصيات البحث:

يسـتوجب إدراك أهمية وجود المبانى الخضــــراء وأنظمة تقييمها فى مصــر ، بهدف التوصــل الى مســتقبل أفضــل للبيئة 
2. ضـرورة الإهتمام بعمل التصـميم البيئى للمبنى، وأهمية وكيفية

إستخدام الحاسب الآلى لحساب الطاقةالمستخدمة بالمبنى.

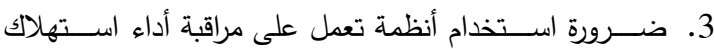

الطاقة، وإلزام تواجدها بالمبانى التى تســتهلك قدر كبير من هن

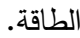

\section{التوصيات الخاصة بجودة البيئة الداخلية:}

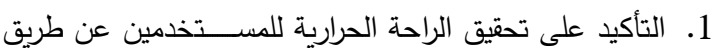

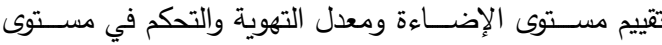

$$
\text { الضوضاء. }
$$

2. ضرورة التحكم فى التدخين داخل وحول المبنى.

3. الإهتمام بتوفير بيئة صـحية من خلال التهوية الجيدة للأماكن

المغلقة، وحمايـة مســـتخدمي المبنى من التعرض للملوثات

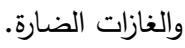

التوصيات الخاصة بكفاءة إدارة المواد:

$-\infty$

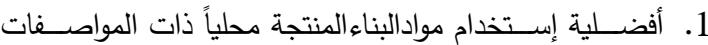

الخضراء والغير ملوثة للبيئة.

2. إمكانية إستخدام مواد البناءمنخفضـة الانبعاثات، ويقدم شهادة

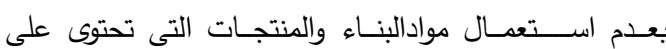

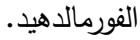

3. ضـــرورة تحليل ودراســــة جدوى لتكلفة موادالبناء، وإمكانية

صيانتها على مدار دورة حياة المبنى. و - التوصيات الخاصة بكفاءة إدارة المخلفات:

1. الإهتمام بزيادة الوعى بأهمية تدوير المخلفات، وتوفير أماكن

لفرز القمامة للنظ رفى إعادة استخدامها وتدويرها.

2. دراسة إعادةإستخدام وتوظيف المباني القائمة.

3. التركيز على إعادة اسـتعمالالموادالتى يمكن إعادةتدويرها مثل:

(الحديد- الخرسانة- الركام- المخلفاتالزراعية)

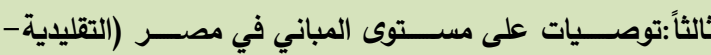

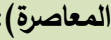

1. ضرورة التوصل إلى ايجاد عمارة خضراء معاصـرة تتنمي الي

البيئة التقليدية المحلية فى مصر •

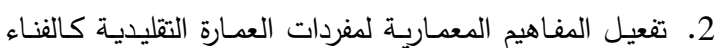

وملقف الهواء والمشربيات وعناصر التظليل والتحكم بالاضـاءة

الطبيعية وأسـاليب العزل الحراري باستخدام مواد البناء المحلية

والتقنيات الطبيعية التي كانت تستخدم لترطيب الهواء وتبريده،

وتوظيفها في المباني المعاصـرة والاسـعانة بالدراسـات العلمية

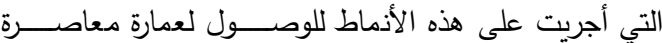

خضراء تلاءم البيئة المحلية.

\section{References}

[1] Amal Mohamed Taha - A proposed methodology for evaluating green buildings in Egypt - Ph.D. 2014 - Faculty of Engineering, Assiut University.
بالإنسـان والبيئة، حيث وصـلت نقاط تقييم البند إلى 11

نقطة بنسبة 7\%.

و - إدارة النفايات:يهدف الى تجميع وفرز وتدوير نفايات

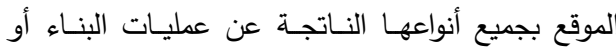

التشغيل أو الصيانة، للاستفادة منها والتخلص من الباقي

بالطرق الغير ضـار بالبيئة، وصـلت نقاط تقييم البند إلى لى لـ

13 نقطة بنسبة 99\%.

5. من خلال نتائج تقييم نماذج المباني التقليدية والمعاصـــرة في

مصر ، نجد أن المباني التقليدية تمثل عدة مبادئ واستراتيجيات

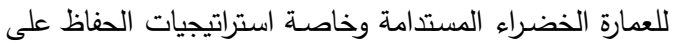

الطاقة وجودة البيئة الداخلية.

6. توصلت الورقة البحثية من خلال تقييم لنماذج للمباني التقليدية

(بيت الســيمي- بيت الكريتيلية)، ونماذج للمباني المعاصـرة

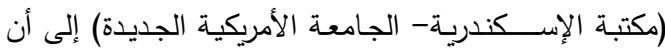

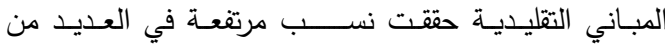

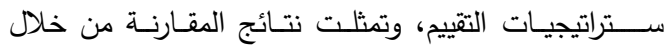

استراتيجيات استدامة المباني الخضراء.

2-6

خلصـت الدراسـة إلى بعض التوصـيات التى تسـاهم في

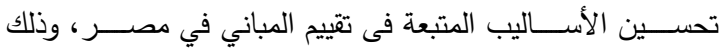

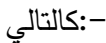

أولا: توصيات على مستوى مجالات تقييم الإستدامة البيئية: التوصيات الخاصة باستدامة الموقع:

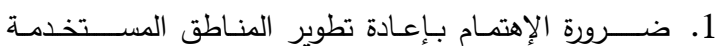

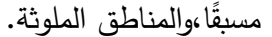

2. ضــرورة توفير وســائل النقل العام،والتشــيع على إســتخدام

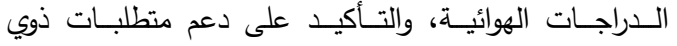

الاحتياجات الخاصة.

3. سهولة الوصول إلى الخدمات بطرق أكثر استدامة بدون

إحداث أي تأثيرات سلبية على البيئة.

التوصيات الخاصة بكفاءة استخدام المياه:

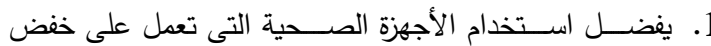

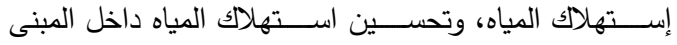

$$
\text { وخارجه. }
$$

2. الإهتمام بعمل حملات توعية للتشــيع على تقليل إبــتهلاك

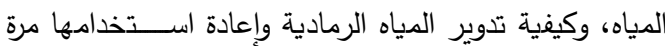

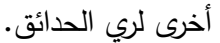

3. ضـرورة العمل على توفير أدوات لقياس استهلاك المياه يسهل لحكل

الوصول إليهامن خلال عدادات المياه.

ج- - التوصيات الخاصة بكفاءة استخدام الطاقة:

1. التأكيد على استخدام الطاقة المتجددة، وتشجيع استخدام لمبات

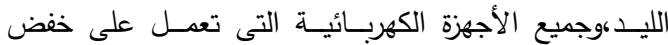

إستهلاك الطاقة. 
[10] Nermine Abdel Gelil Mohamed- Traditional Residential Architecture in Cairo from a GreenArchitecture Perspective- Department of Architecture, Faculty of Engineering, October University for Modern Sciences and Arts (MSAUniversity), 6th of October City, Egypt2014.

[11] Sam Kubba, "LEED® Practices, Certification, and Accreditation Handbook", phd,British Library, LEED AP, Elsevier Inc., USA, 2010.

[12] Sherin Hisham Sameh Hussein, "An approach for sustainable Architecture in Egypt adaptation ofLeadership in Energy and Environmental Design (LEED) checklist to suit the Egyptian context", M.Sc.,Architectural Department, Faculty of Engineering, Cairo University, Egypt, 2008.

[13] http://www.epods-ye.org

[14] http://estidama.org/Estidama

[15] http://www.adm.gov.ae/ar/home/index.aspx

[16] http://www.egyptgbc.gov.eg

[17] www.wikibidia.com/Accessed in 22/10/2018.

[18] The Arab Republic of Egypt, Ministry of Housing, Utilities and Urban Development, The Housing and Building National Research Center, The Egyptian Green Building Council, "The Green Pyramid RatingSystem (GPRS)", First Edition, April 2011/Accessed in 22/10/2018.

[19] http://www.bonah.org/home.php

[20]www.egyptarch.net/historicalcairo/islamicmon ements/kritliahouse/kretliamain Accessed in 20/10/2018

[21] http://www.arabcont.com/projects/project78.aspx

[22] AUC "New Cairo Campus: Making History Again" Official Sitehttp //aucegypt.edu Accessed $3 \backslash 10 \backslash 2018$.
[2] Ismail Serageldin - An impressive building Reflections on the architectural structure of the Library of Alexandria - Bibliotheca Alexandrina 2007.

[3] Khaled Khalil Muhammad Al-Kubaisi, "Development and Analysis of the Financial Cost and Benefits of High Performance Buildings Model in Iraq - PhD Thesis, Arab Open Academy, Project Management Department, College of Business and Economics, Denmark, 2011.

[4] Mohamed Abdel Fattah Ahmed El-Essawy The Effect of Building Envelope Design on Heat Gain and Thermal Comfort for Users - Approach to Environmental Design Process for Building Envelope, Master Thesis, Environmental Design, Department of Architecture, Faculty of Engineering, Cairo University, Egypt, 2003.

[5] Tamer Rafat - Green Design Standards and Energy Efficiency in Administrative Buildings Department of Architecture, Canadian International College, Cairo - Published Research Journal of the Faculty of Engineering, Assiut University-2018.

[6] Shadia Mohamed Barakat, Nemat Mohamed Nazmy - Sustainable Design of Green Architecture between Past and Present - Published Research The First International Engineering Conference "Hosting Major International Events: Innovation, Creativity and Impact Assessment - January 2013.

[7] HEBAALLA MOSTAFA KARMANYEVALUATION OF GREEN BUILDING RATING SYSTEMS FOR EGYPT- Master of Science in Sustainable Development- The American University in Cairo- 2016.

[8] Jeremy Gibberd, "Integrating Sustainable Development into Briefing and Design Processes of BuildingsinDeveloping Countries: An Assessment Tool", PhD, Department of Architecture, University of Pretoria,South Africa, 2003.

[9] Mels Crouwel "Green Architecture, 5 sustainable buildings", Atelier Rijksbouwmeester, Netherlands, June 2008. 